\title{
TLR4 Activity Is Required in the Resolution of Pulmonary Inflammation and Fibrosis after Acute and Chronic Lung Injury
}

\author{
Hong-Zhen Yang, ${ }^{*}$ Jia-Ping Wang, ${ }^{*}$ Su Mi, ${ }^{*}$ \\ Han-Zhi Liu, ${ }^{*}$ Bing Cui, ${ }^{*}$ Hui-Min Yan, ${ }^{*}$ Jun Yan, ${ }^{*}$ \\ Zhe Li, ${ }^{*}$ Hong Liu, ${ }^{*}$ Fang Hua, ${ }^{*}$ Wange $\mathrm{Lu},{ }^{\dagger}$ and \\ Zhuo-Wei Hu*

\begin{abstract}
From the Molecular Immunology and Pharmacology Laboratory," State Key Laboratory of Bioactive Substances and Functions of Natural Medicines, Institute of Materia Medica, Chinese Academy of Medical Sciences and Peking Union Medical College, Molecular Biology, ${ }^{\dagger}$ Eli and Edythe Broad Center for Regenerative Medicine and Stem Cell Research, University of Southern California Keck School of Medicine, Los Angeles, California
\end{abstract} \\ Beijing, China; and the Department of Biochemistry and
}

Pulmonary fibrosis is an inflammation-driven lung disease with a poor prognosis and no cure. Here we report that basal toll-like receptor 4 (TLR4) activity is critical for the resolution of acute and chronic inflammation and pulmonary fibrosis in mouse models of lung injury. We found that genetic or pharmacologic inhibition of TLR4 exacerbates bleomycin-induced pulmonary inflammation, fibrosis, dysfunction, and animal death through promoting formation of an immunosuppressive tissue microenvironment and attenuating autophagy-associated degradation of collagen and cell death in the fibrotic lung tissues. In contrast, pharmacologic activation of TLR4 resulted in a quick resolution of acute inflammation, reversed the established pulmonary fibrosis, improved lung function, and rescued mice from death. Similarly, blocking TLR4 impaired the resolution of silica-induced chronic inflammation and fibrosis. Importantly, altering autophagic activity could reverse the TLR4-regulated lung inflammation, fibrosis, dysfunction, and animal death. Rapamycin, an autophagy activator, reversed the effects of TLR4 antagonism. In contrast, inhibition of autophagy by 3-methyladenine reversed the proresolving and antifibrotic roles of TLR4 agonists and increased animal death. These results not only highlight a pivotal role for TLR4-mediated basal immunity, particularly autophagic activity, in the proresolution of inflammation and fibrosis after chem- ical-induced lung injury but also provide proof for the concept for activating TLR4 signaling, particularly TLR4mediated autophagy, as a novel therapeutic strategy against chronic fibroproliferative diseases that are unresponsive to current therapy. (Am J Pathol 2012, 180: 275-292; DOI: 10.1016/j.ajpath.2011.09.019)

Fibroproliferative diseases are characterized by chronic inflammatory response and tissue fibrosis and often result in severe disruption of organ structure and function. A fatal outcome is possible after tissue injury caused by microbial infection, chemical agents, stress, and drugs. ${ }^{1,2}$ Despite recent improved insights into disease pathogenesis and identification of new molecular targets, the precise pathologic mechanisms and, particularly, an effective drug therapy for fibroproliferative diseases has yet to be identified. ${ }^{1,3,4}$ Indeed, based on observations from clinical trials and animal studies, especially the fact that immunosuppressive and anti-inflammatory agents are relatively ineffective against tissue fibrosis, it is increasingly questioned whether inflammation is a major component of established

Supported by grants from the National Natural Science Foundation (30672468 to Z.-W.H.; 30901814 to H.-Z.Y.), Major Program of National Natural Science Foundation (81030056 to Z.-W.H.), Creation of Major New Drugs (2009ZX09301-003-13 to Z.-W.H.), Beijing Natural Science Foundation (7102113 to H.-Z.Y.), National Major Basic Research Program of China (2006CB503808 to Z.-W.H.), and Fundamental Research Funds for the Central Research Institute (2011CHX02 to H.-Z.Y.)

Accepted for publication September 30, 2011.

H.-Z. Yang and J.-P. Wang contributed equally to this work.

Author contributions: H.-Z.Y. and J.-P.W. performed most experiments and analyzed and interpreted data; S.M., H.-Z.L., B.C., H.-M.Y., J.Y., Z.L., H.L., and F.H. conducted and analyzed some experiments; W.-G.L. revised the manuscript; H.-Z.Y wrote the manuscript; and Z.-W.H. conceived and designed the experiments, interpreted the data, and wrote the manuscript.

Supplemental material for this article can be found at http://ajp. amjpathol.org or at doi: 10.1016/j.ajpath.2011.09.019.

Address reprint requests to Zhuo-Wei Hu, M.D., Ph.D., Molecular Immunology and Pharmacology Laboratory, Institute of Materia Medica, Chinese Academy of Medical Sciences and Peking Union Medical College, 2 Nan Wei Rd., Beijing 100050, China. E-mail: huzhuowei@imm.ac.cn. 
fibrotic pathologic conditions. ${ }^{2,5}$ Moreover, recent clinical trials for idiopathic pulmonary fibrosis (IPF) failed to identify unequivocally a survival benefit after testing a number of agents with various mechanisms of action, including pirfenidone, bosentan, etanercept, interferons, $\mathrm{N}$-acetylcysteine, warfarin, the protein kinase inhibitor imatinib, and the phosphodiesterase- 5 inhibitor sildenafil. ${ }^{6,7}$ As a result, there is an urgent need to develop safe and effective therapeutic agents for fibroproliferative diseases.

Despite controversy, we believe that acute and chronic inflammation plays a critical role in the initiation and progression of tissue fibrosis after acute tissue injury caused by a variety of insults. ${ }^{2,8}$ The inflammation is elicited through diverse molecules with pathogen- or damage-associated molecular patterns interacting with pattern recognition receptors, which include toll-like receptors (TLRs), RIG-1-like receptors, NOD-like receptors, and C-type lectin receptors. ${ }^{9}$ The properties, duration, and intensity of the inflammatory response, rather than inflammation per se, direct the development and progression of tissue fibrosis. ${ }^{10}$ Our previous studies have indicated that TLR2 mediates bleomycin (BLM)-induced acute lung injury, pulmonary inflammation, and fibrosis and that blocking TLR2 activity promotes the resolution of pulmonary inflammation and fibrosis. ${ }^{11}$ In most situations, TLR4 and TLR2 play similar roles in the mediation of inflammatory response because they share many common ligands and a common inflammatory signaling pathway. ${ }^{12}$ Moreover, Imai et $\mathrm{al}^{13}$ recently reported that acute lung injury caused by multiple lung pathogens is triggered by the signaling of oxidized phospholipids through activation of TLR4. Seki et $\mathrm{al}^{14}$ found that activation of TLR4 enhances transforming growth factor (TGF)- $\beta$ signaling in the development of hepatic fibrosis. We and others observed that TLR4 mediates pressure overload-induced cardiovascular fibrosis and remodeling through activation of a chronic inflammatory response. ${ }^{15,16}$

We therefore hypothesized that inhibition of TLR4 signaling was able to protect mice from lung injury, acute and chronic inflammation, lung dysfunction, and pulmonary fibrosis after acute or chronic lung injury caused by chemical agents. Unexpectedly, our studies demonstrated an opposite effect of TLR4 antagonism on the BLM- or silica-induced mouse models of acute or chronic lung injury. We found that the basal TLR4 activity, particularly the TLR4mediated activation of autophagy, is crucial to maintain an optimal tissue environment and to promote the resolution of acute or chronic inflammation and fibrogenesis after acute or chronic lung injury. Our results suggest that the immunostimulants eliciting autophagic activity, such as TLR4 agonists, instead of immunosuppressive agents, may be a promising therapeutic strategy for the treatment of devastating fibroproliferative diseases such as IPF.

\section{Materials and Methods}

\section{Reagents}

EC-LPS (purified from Escherichia coli 0111: B4 strain, TLR4 agonist) [Lipopolysaccaride (LPS)-EB Ultrapure] was obtained from InvivoGen (San Diego, CA). Alexa
Fluor 488-, Alexa Fluor 555-, or Alexa Fluor 647-conjugated anti-mouse CD4, CD25, FoxP3, PDCA-1, F4/80, CD206, CD11b, and TLR4 (clone UT41) antibodies were purchased from eBioscience (San Diego, CA). An annexin V/propidium iodide (PI) apoptosis assay kit was obtained from SBA Sciences (Turku, Finland). TLR4-neutralizing monoclonal antibody (mAb) (clone MTS510, \#117608) was obtained from BioLegend (San Diego, $\mathrm{CA}$ ). The blocking effects of the TLR4-neutralizing mAb were verified as described previously. ${ }^{17}$ The anti- $\alpha$ smooth muscle actin (SMA), $\beta$-actin, glyceraldehyde-3phosphate dehydrogenase, apoptosis signal-regulating kinase 1 (ASK1), phospho-ASK1, active (cleaved) caspase 3, p38 mitogen-activated protein kinase (MAPK), phosphop38 MAPK, JNK, phospho-JNK, ERK, phospho-ERK, $\beta$-tubulin, NF- $\kappa$ B, phospho-NF- $\kappa$ B, mammalian target of rapamycin (mTOR), phospho-mTOR, Akt, and phospho-Akt antibodies were purchased from Cell Signaling Technology Inc. (Danvers, MA). The anti-LC3B, Beclin1, PI3K3C, and LAMP1 antibodies were from Abcam (Cambridge, UK).

ECL Plus Western blotting detection reagents were from Amersham Biosciences (Piscataway, NJ). Bleomycin (BLM, $1 \mathrm{U} / \mathrm{mg}$ ) was from Nippon Kayaku (Tokyo, Japan). Rapamycin and 3-methyladenine (3-MA) were from Sigma-Aldrich (Shanghai, China). Pulmonary hydroxyproline levels were evaluated with a commercially available kit (Nanjing Jiancheng Institute of Biotechnology, Nanjing, China). The endotoxin level in the solutions of BLM and neutralizing Abs was $<0.01 \mathrm{ng} / \mathrm{mL}$, as tested by the Limulus amebocyte lysate assay (BioWhittaker, Walkersville, MD). The reactive oxygen species (ROS) testing kit was purchased from Genmed Scientifics Inc. (Shanghai, China). All other materials were purchased from standard commercial sources.

\section{Animal Models}

TLR4-deficient (TLR4 ${ }^{-1-}$ ) and corresponding wild-type (WT) mice $(\mathrm{C} 3 \mathrm{H})$ were purchased from Model Animal Research Center of Nanjing University (Nanjing, China). C57BL/6J mice (18 $\mathrm{g} \pm 1 \mathrm{~g}, 6$ to 8 weeks old) were obtained from the Vital River Lab Animal Technology, Co. Ltd. (Beijing, China). The animals were housed in a facility with a 12-hour light/12-hour dark cycle and were given free access to water and standard rodent chow. The room was kept free of specific pathogens. The care and treatment of experimental animals was in accordance with institutional guidelines at the Experimental Animal Center of the Chinese Academy of Medical Sciences.

To generate the animal model of acute inflammation and pulmonary fibrosis, mice were anesthetized with i.p. pentobarbital (50 mg/kg) (Merck, Woodbridge, NJ) and injected intratracheally with BLM $(3.0 \mathrm{mg} / \mathrm{kg})$ in $50 \mu \mathrm{L}$ of LPS-free saline using an insulin syringe as previously described. ${ }^{11}$ To determine the effects of targeting TLR4 on established pulmonary fibrosis, ${ }^{18}$ i.v. TLR4-neutralizing or isotype-matched antibody $(200 \mu \mathrm{g} / \mathrm{kg}$ in $200 \mu \mathrm{L}$ saline) was injected on the tenth and 17th days after BLM instillation; i.p. TLR4 agonist Ec-LPS (10 mg/kg/day) was injected once daily from day 10 to day 17 after BLM instillation. 
To determine the roles of autophagy in TLR4-regulated pulmonary fibrosis, i.p anti-TLR4 antibody was given with or without rapamycin ( $10 \mathrm{mg} / \mathrm{kg} /$ day from day 9 to day 17 after BLM instillation), whereas i.p. Ec-LPS was given with or without 3-MA (30 mg/kg/day from day 9 to day 17 after BLM instillation). Four weeks after BLM administration, the mice were sacrificed by excessive anesthesia for the collection of single-cell suspensions, bronchoalveolar lavage fluid (BALF), and lungs at the indicated time points. The lungs were excised and fixed or frozen for morphologic evaluation, analysis of cytokine and chemokine expression, or the measurement of hydroxyproline content.

To generate a mouse model of chronic inflammation and fibrosis, $\mathrm{C} 57 \mathrm{BL} / 6 \mathrm{~J}$ mice were administered $\mathrm{SiO}_{2}(2.5$ $\mathrm{mg} /$ mouse) intratracheally as described previously, ${ }^{11}$ and a TLR4-neutralizing or isotype-matched antibody $(200 \mu \mathrm{g} / \mathrm{kg})$ was administered intravenously once a week from day 14 after $\mathrm{SiO}_{2}$ treatment. Two months after $\mathrm{SiO}_{2}$ administration, animals were used for measuring lung function or sacrificed by excessive anesthesia for the collection of lungs and BALF for the indicated analysis.

\section{Lung Function}

At the end of the experiment, the mice were anesthetized, underwent tracheostomy, and were placed in a forced pulmonary maneuver system (Buxco Research Systems, Wilmington, NC) as described previously. ${ }^{19}$ Lung compliance (Cchord) and functional residual capacity (FRC) were measured. All data reflect measurements from at least 5 mice per group.

\section{Acquisition of Microcomputed Tomography Images}

Microcomputed tomography (micro-CT) images were generated as described previously. ${ }^{20}$ Animals were anesthetized with i.p. chloral hydrate $(400 \mathrm{mg} / \mathrm{kg}$ ) to achieve prolonged sedation. The animals were intubated perorally, placed on an acrylic cradle, and suspended vertically for imaging. $X$-ray parameters were as follows: 80 kilovolts (peak) [kV(p)], $220 \mathrm{~mA}$, and 12-msec exposure per projection. Five hundred ten projections were acquired at a 0.725 -degree increment between projections for a total rotation angle of 370 degrees. Data were reconstructed with weighting according to Parker as isotropic $512 \times 512 \times 512$ arrays with effective digital sampling of $100 \mu \mathrm{m}$ along all three axes. Reconstructed images were converted to Hounsfield units $(\mathrm{HU})$ by scaling air selected from a region outside the animal to $-1000 \mathrm{HU}$ and water to $0 \mathrm{HU}$ using a waterfilled phantom secured to the abdomen of each animal via a conversion file written for MATLAB (The MathWorks, Natick, MA).

\section{Preparation of BALF}

BALF was collected and processed as previously described. ${ }^{11}$ In brief, the trachea was exposed through a midline incision and cannulated with a sterile 22-gauge
Abbocath-T catheter. Bilateral BAL was performed by instilling two $0.5-\mathrm{mL}$ aliquots of sterile saline. Approximately 0.9 to $1.0 \mathrm{~mL}$ of BALF was retrieved per mouse. The cellular viabilities assessed by $0.4 \%$ trypan blue exclusion were greater than $99 \%$. The total cell count of the BALF was assessed with a hemocytometer (Neubauer Zählkammer, Gehrden, Germany). The cells were then washed, resuspended, and analyzed by a hematology analyzer or stained with PE-Cy5-, APC- or fluorescein isothiocyanate (FITC)-conjugated antibodies for flow cytometry. The concentrations of interferon (IFN)- $\gamma$, TGF- $\beta 1$, interleukin (IL)-4, IL-5, IL-10, and IL-13 in BALF were measured with enzyme-linked immunoassay kits following the manufacturer's instructions.

\section{Flow Cytometry}

The immune cells in BALF were analyzed using flow cytometry as described previously. ${ }^{21}$ In brief, BALF was harvested, washed, and suspended in cold phosphatebuffered saline containing $3 \%$ fetal bovine serum, and $0.02 \% \mathrm{NaN}_{3}$. The cells were then incubated with a mixture of rat and mouse IgG (1:1) to block nonspecific binding, followed by serial incubations with Alexa Fluor 488-, Alexa Fluor 568-, and/or Alexa Fluor 647-conjugated mAb for 1 hour at $4^{\circ} \mathrm{C}$. Isotype-matched mAbs were used in control samples. After incubation, $\mathrm{Foxp}^{+} \mathrm{CD}^{+} \mathrm{CD}^{+} 5^{+}$regulatory $\mathrm{T}$ cells $\left(\mathrm{Foxp}^{+} \mathrm{T}_{\text {reg }} \mathrm{s}\right.$ ), $\mathrm{PDCA}^{+}$plasmacytoid dendritic cells (pDCs), CD11 b ${ }^{+} \mathrm{F} 4 / 80^{+} \mathrm{CD}^{2} 6^{-} \mathrm{M} 1$ macrophages, and $\mathrm{CD} 11 \mathrm{~b}^{+} \mathrm{F} 4 / 80^{+} \mathrm{CD} 206^{+} \mathrm{M} 2$ macrophages were analyzed using CellQuest software (Becton Dickinson, $C A)$.

\section{Morphologic Evaluation of Lung Sections}

At the end of the experiment, the lungs were rapidly excised, fixed with $4 \%$ paraformaldehyde, and embedded in paraffin for histopathologic examination. Tissue sections $(5-\mu \mathrm{m}$ thick) were prepared and stained with H\&E or Masson's trichrome. The grades of pulmonary inflammation and fibrosis were analyzed by a professional pathologist, who was blinded for groups. The average integrated optical density of the collagen deposition was determined by Image-Pro Plus image analysis software (Media Cybernetics, Silver Spring, MD) in 10 randomly chosen regions per tissue sample at a magnification of $\times 200$.

\section{Measurement of Lung Hydroxyproline}

Collagen deposition was also determined by measuring the total hydroxyproline content of the lungs according to Reddy's method, with modifications. ${ }^{11}$ In brief, the lungs were hydrolyzed with $2.5 \mathrm{~N} \mathrm{NaOH}$ at $120^{\circ} \mathrm{C} 0.1 \mathrm{kPa}$ for 40 minutes. After neutralization with hydrochloric acid, the hydrolysates were diluted with distilled water. Hydroxyproline in the hydrolysates was assessed calorimetrically at $550 \mathrm{~nm}$ with $p$-dimethylaminobenzaldehyde. Results are presented as micrograms per milligrams of wet lung. 


\section{TUNEL Assay}

Lung sections (5- $\mu \mathrm{m}$ thick) were prepared as described earlier, and apoptosis was detected by TUNEL using the ApopTag Peroxidase in Situ Apoptosis Detection Kit (Millipore, Billerica, MA). The lung sections were stained and TUNEL-positive cells were counted according to the manufacturer's protocol. ${ }^{22}$

\section{Assay for Collagen I Degradation}

JHU-1 cells were obtained from ATCC (CRL-2785; Manassas, VA) and cultured in medium without serum and treated with FITC-labeled collagen for 30 minutes as previously described. ${ }^{23}$ The cells were then rinsed with phosphate-buffered saline three times. The cells were then cultured in microplate Alomar blue assay medium and treated with the indicated agents for 3 hours. Cells were washed, collected, and suspended in cold phosphate-buffered saline containing 3\% fetal bovine serum and $0.02 \% \mathrm{NaN}_{3}$. Fifty thousands cells were analyzed using CellQuest software (BD Biosciences).

\section{Measurement of ROS}

Total ROS production in the lungs was measured using 2 ', $7^{\prime}$-dichlorofluorescein diacetate according to the manufacturer's protocol. ${ }^{24}$ Data were analyzed with the LSM510 software (Carl Ziess, Göttingen Germany) and presented as the fluorescence intensity of ROS (arbitrary units).

\section{Measurement of Autophagy}

Autophagy was evaluated by immunofluorescence microscopy, electron microscopy, or immunoblot as described previously. ${ }^{25}$ In the immunofluorescence microscopy experiments, autophagy was evaluated by examining the punctate forms of the autophagy marker LC3 and the co-localization of LC3 and the lysosome marker LAMP1. ${ }^{26}$ Quantification of autophagy was performed based on the percentage of cells with LC3-containing punctate dots. In electron microscopy experiments, autophagy was evaluated by observing the typical double-membrane vesicles and quantified by the number of autophagic vacuoles per cross-sectioned cell. In all experiments, six samples were counted per experimental condition. ${ }^{11}$

\section{Western Blot}

Proteins were extracted from lung tissues using a Qproteome Plasma Nuclei Protein Kit (Qiagen Inc., Valencia, CA). Protein concentrations were determined with Coomassie Plus reagent. Sodium dodecyl sulfate polyacrylamide gel electrophoresis and Western blot were conducted as described previously. ${ }^{17}$

\section{Confocal Microscopy}

Protocols for immunofluorescence microscopy were described previously. ${ }^{27}$ Lung sections (5- $\mu \mathrm{m}$ thick) were prepared and stained with corresponding primary antibodies overnight at $4^{\circ} \mathrm{C}$. The sections were then washed twice and incubated with fluorochrome-labeled secondary antibodies (1:200) for 30 minutes followed by three washes. Images were captured with a Leica SP2 confocal microscope (Leica Microsystems Inc., Exton, PA) and analyzed with Leica confocal software. The autophagosomes were evaluated by the co-expression of LC3 and LAMP1. Autophagic cell death was determined by a combination of LC3 and TUNEL, and autophagic cell apoptosis was determined by the combination of LC3 and active caspase 3 .

\section{Statistics}

Data are presented as mean \pm SD. Statistical analysis was performed with one-way analysis of variance, in which a threshold $P$ value was set at 0.05 , followed by Tukey-Kramer's or Dunnett's post hoc multiple comparison tests. Survival rates were analyzed by the KaplanMeier method.

\section{Results}

\section{TLR4 Deficiency Exacerbates Pulmonary Inflammation and Fibrosis after Acute Lung Injury}

We have found previously that targeting TLR2 markedly attenuates the BLM-induced lung injury, inflammation, and fibrosis via reversal of the BLM-induced immunosuppressive tissue environment. ${ }^{11}$ Because TLR4 plays a pivotal role in the initiation and orchestration of the inflammatory response to a variety of lung pathogens, we wondered if blocking TLR4 also attenuates BLM-induced pulmonary inflammation and fibrosis.

Unexpectedly, we found that TLR4 deficiency notably increased the levels of lung injury, pulmonary inflammation, and fibrosis after BLM treatment. TLR4-deficient $\left(\mathrm{TLR}^{-1-}\right.$ ) mice exhibited markedly enhanced pulmonary fibrosis, as indicated by increased collagen deposition, $\alpha$-SMA expression, and hydroxyproline content in the lungs (Figure 1A-E). Also, TLR4 deficiency significantly increased pulmonary inflammation (Figure 1, A and B) and infiltration of inflammatory cells, including total white blood cells, lymphocytes, neutrophils, basophils, eosinophils, and macrophages in BALF (see Supplemental Table S1 at http://ajp.amjpathol.org).

Consistent with these pulmonary structural changes and inflammatory status, BLM-treated WT animals presented a significant reduction in lung function. TLR4 deficiency caused a further decline in lung function, as indicated by decreases in Cchord and FRC (Figure 1F), as well as other parameters of lung function (see Supplemental Figure S1 at http://ajp.amjpathol.org). Additionally, micro-CT was used to obtain three-dimensional informa- 
A

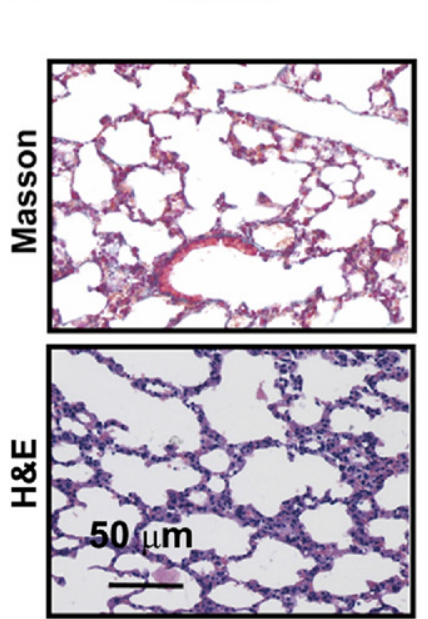

BLM
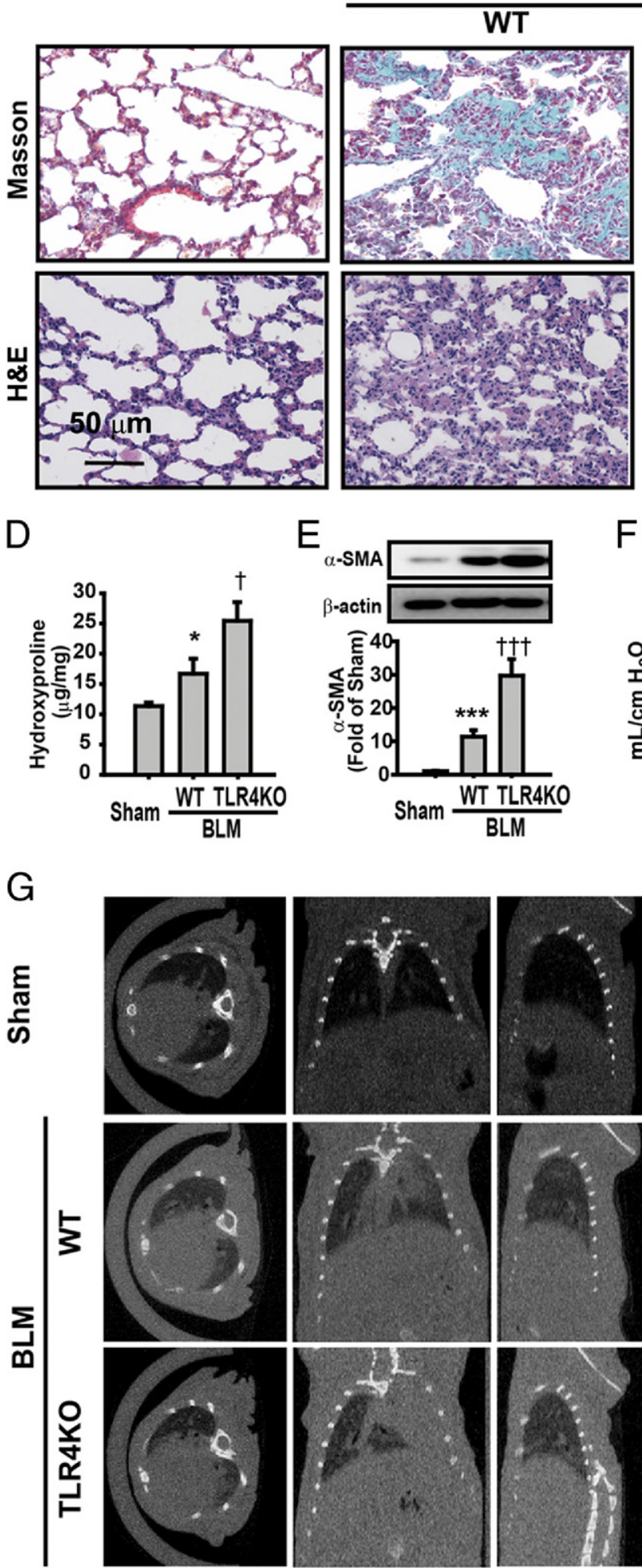

E

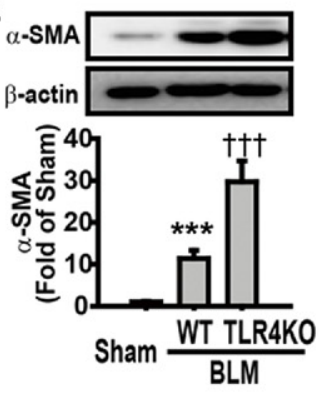

F
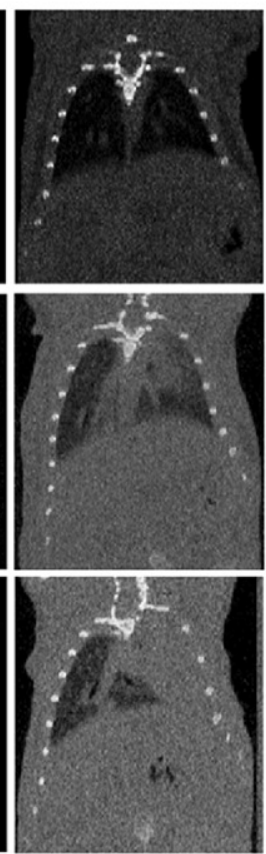
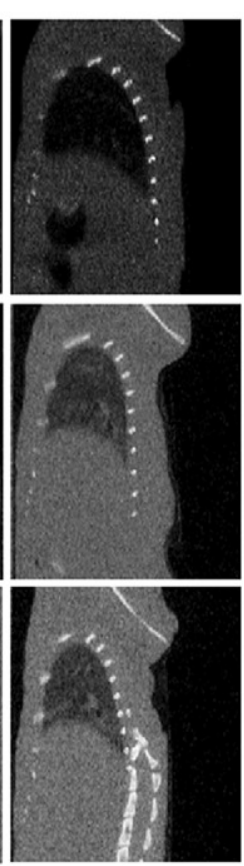
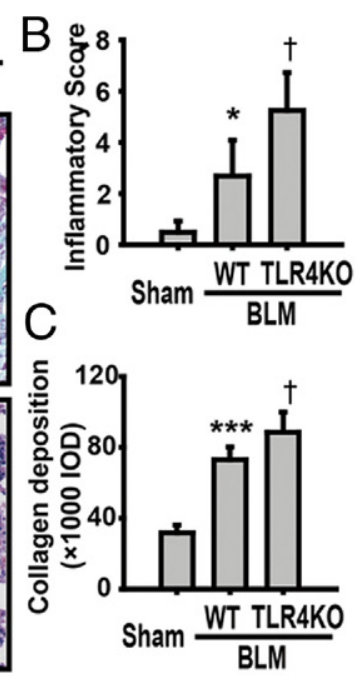

FRC
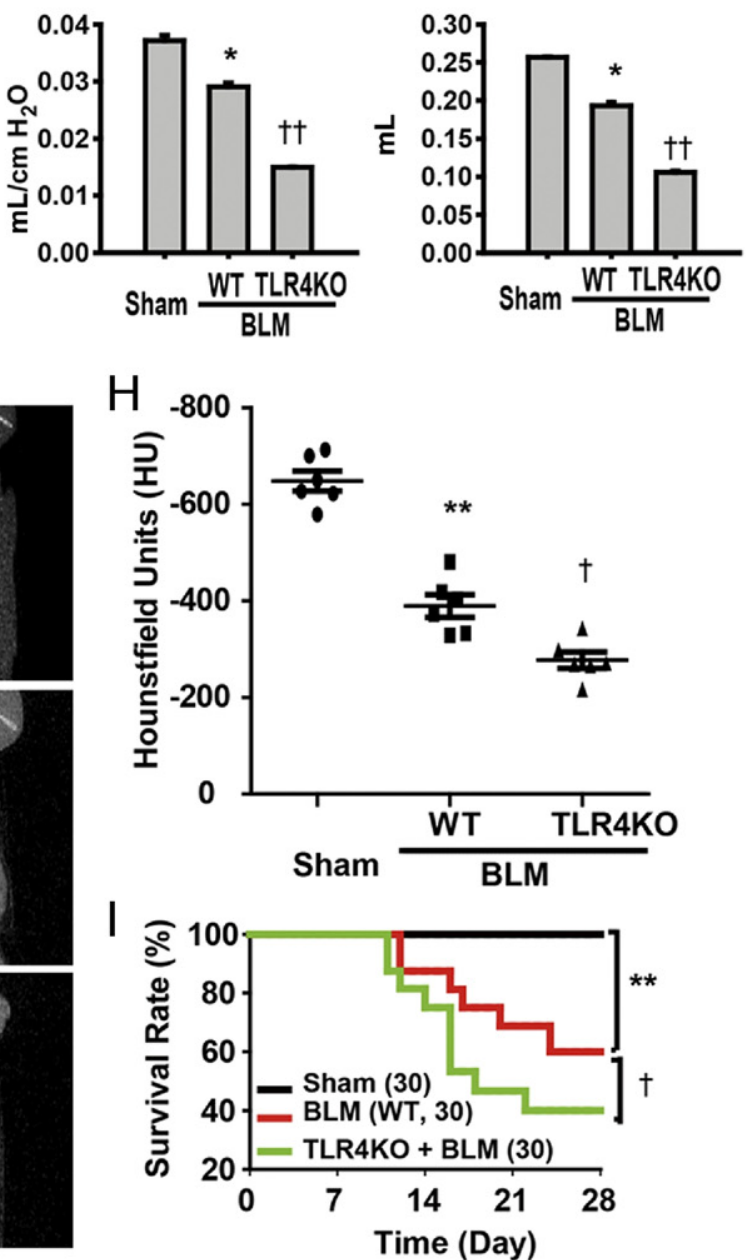

Figure 1. TLR4 deficiency impairs the resolution of pulmonary inflammation and aggravated pulmonary fibrosis after bleomycin (BLM)-induced acute lung injury. TLR4 ${ }^{-/-}$or wild type (WT) mice were administered BLM $(3 \mathrm{mg} / \mathrm{kg}$ ) intratracheally and sacrificed after 28 days. A-E. TLR4 deficiency enhanced the pulmonary inflammation and fibrosis. Data are representative photomicrographs of Masson's trichrome and H\&E staining of lung sections (A), summary of inflammatory scores (B), summary of collagen deposition (C), summary of hydroxyproline content (D), and the expression of $\alpha$-smooth muscle actin ( $\alpha$-SMA) (E) in the lungs. Data are presented as the mean \pm SD of three independent experiments ( $n=8$ /group/experiment). F: TLR4 deficiency aggregated the lung function of BLM-treated mice. Data are summary of lung compliance (Cchord) (left panel) and summary of functional residual capacity (FRC) (right panel). Other parameters of lung function are presented in Supplemental Figure S1 (available at bttp://ajp.amjpathol.org). Data are presented as the mean $\pm \mathrm{SD}$ of three independent experiments ( $n=6$ /group/experiment). G: Representative microcomputed tomography (micro-CT) images. H: Summary of CT values. Reconstructed images were converted to HUs by scaling air selected from a region outside the animal to - $1000 \mathrm{HU}$ and water to $0 \mathrm{HU}$ using a water-filled phantom secured to the abdomen of each animal, via a conversion file written for MATLAB. I: TLR4 deficiency further increased the BLM-induced animal death. The cumulative survival rates of mice were analyzed by the Kaplan-Meier method $(n=30) .{ }^{*} P<0.05,{ }^{* * *} P<0.01$, and ${ }^{* * * * * *} P<0.001$ compared with Sham mice; ${ }^{\dagger} P<0.05$, ${ }^{t} P<0.01$, and ${ }^{+1 t} P<0.001$ compared with BLM-treated mice. IOD, integrated optical density. 
tion about lung structure. The BLM-treated TLR4 ${ }^{-1-}$ mice exhibited a significant reduction in lung density, as represented by a reduction in $H U$ values, compared with BLM-treated WT mice (Figure 1, G and H). As a result, TLR4 deficiency reduced the survival rate of BLM-treated mice (Figure 1I).

\section{TLR4 Deficiency Interferes with Resolution of Inflammation and Promotes the Formation of an Immunosuppressive Microenvironment in BLM-Injured Lungs}

After acute lung injury, a Th1-predominant immune response is necessary for the resolution of inflammation and fibrosis, whereas a Th2-predominant immune response contributes to the development of chronic inflammation and fibrosis. ${ }^{11}$ Therefore we investigated the effect of TLR4 deficiency on immune regulation in the pulmonary microenvironment by examining the recruitment of immune cells and the secretion of cytokines and chemokines.

The numbers of lung-infiltrating $\mathrm{FoxP}^{+} \mathrm{T}_{\text {reg }} \mathrm{s}$, $\mathrm{PDCA}^{+}$pDCs, and $\mathrm{M} 1$ and $\mathrm{M} 2$ macrophages (see Supplemental Figure S2, A-D at http://ajp.amjpathol. org) were significantly increased in BLM-injured WT mice compared with untreated WT mice. TLR4 deficiency further increased the infiltration of $T_{\text {reg }} s, p D C s$, and M2 macrophages (see Supplemental Figure S2, A, $\mathrm{B}$, and $\mathrm{D}$ at http://ajp.amjpathol.org) but not the infiltration of M1 macrophages (see Supplemental Figure S2C at http://ajp.amjpathol. org). Additionally, TLR4 deficiency reduced the production of the Th1 cytokine IFN- $\gamma$ (see Supplemental Figure S2E at http://ajp.amjpathol.org) and enhanced the levels of the immunosuppressive cytokines TGF- $\beta$ 1, IL-4, IL-5, IL-10, and IL-13 (see Supplemental Figure S2, F-J at http://ajp.amjpathol.org) in the lungs.

Taken together, TLR4 deficiency interfered with the resolution of BLM-induced inflammation and sustained immunosuppressive response in the injured lung tissue, which contributed to the development of pulmonary fibrosis after acute lung injury.

The MAPK-NF- $\kappa$ B signaling pathway plays a critical role in TLR4-mediated inflammatory responses ${ }^{17,28}$ and in BLM-induced lung injury. ${ }^{11}$ We found that BLM treatment significantly inhibited the expression of ASK1 (Figure 2, A and B) as well as the phosphorylation of ASK1, p38 MAPK, and JNK (Figure 2, C, D, F, G, and I) in WT mice, although it enhanced the expression of p38 MAPK, JNK, and NF- $\kappa$ B (Figure 2, A, B, G, H, M, and $N$ ) and the phosphorylation of ERK and NF- $\kappa$ B (Figure 2, J, L, O, and P). However TLR4 deficiency markedly attenuated the BLM-induced phosphorylation of ASK1, p38, and JNK (Figure 2, C, D, F, G, and I), and enhanced both the expression and phosphorylation of ERK and NF- $\kappa$ B after BLM treatment (Figure 2, J-P). Interestingly, TLR4-deficient mice showed a significant enhancement in the phosphorylation of NF- $\mathrm{BB}$ p65 as well as the p50 subunit after BLM treatment (Figure 2, $\mathrm{O}$ and $\mathrm{P}$ ). These results indicate that the aggravation of BLM-induced pulmonary fibrosis in TLR4-deficient mice was associated with attenuation of the pro-inflammatory p38 signaling pathway and activationba of the immunosuppressive ERK signaling pathway.

\section{Functional Blockade of TLR4 Interferes with the Resolution of Pulmonary Inflammation and Fibrosis}

Considering the likelihood of complex effects of TLR4 deficiency in a knockout animal, such as the potential induction of compensatory mechanisms during development, we examined if blockade of TLR4 activity with a TLR4-neutralizing antibody could also interfere with the resolution of pulmonary inflammation and fibrosis. Because BLM-induced pulmonary fibrosis was primarily established by day 10 after BLM treatment, TLR4neutralizing antibody was administered on day 10 and day 17 after BLM administration. We found that blockade of TLR4 significantly exacerbated the inflammatory response and enhanced collagen deposition, as indicated by increases in hydroxyproline content, the inflammation score, and $\alpha$-SMA expression in the lungs (Figure 3, A-F). TLR4 blockade also significantly reduced lung density, represented by a reduction of $H U$ values, compared with IgG-treated mice (Figure 3, G and $\mathrm{H}$ ). Consequently, functional blockade of TLR4 also further increased BLM-induced animal death (Figure 3I). These data suggest that functional blockade of TLR4 causes an effect similar to that of TLR4 deficiency in the development of pulmonary fibrosis.

To investigate the regulatory effects of TLR4 blockade on the pulmonary immune microenvironment, we analyzed the immune cell profile in BALF and the production of critical cytokines and chemokines in the lungs of $\mathrm{TLR}^{-1-}$ and WT mice. We found that the absence of TLR4 activity increased the infiltration of FoxP3 ${ }^{+} \mathrm{T}_{\text {reg }} \mathrm{S}$, $\mathrm{PDCA}^{+}$pDCs, and M2 macrophages (see Supplemental Figure S3, A, B and D at http://ajp.amjpathol.org) but not M1 macrophages (see Supplemental Figure S3C at http://ajp.amjpathol.org). Moreover, BLM treatment significantly inhibited the secretion of Th1-type cytokines/ chemokines, including IFN- $\gamma$ and CXCL5 (see Supplemental Figure S3, E and K at http://ajp.amjpathol.org), but enhanced the production of Th2-type cytokines/chemokines, including IL-4, IL-5, IL-10, IL-13, TGF- $\beta 1$, and CXCL9 (see Supplemental Figure S3, F-J, and L at $h$ ttp:// ajp.amjpathol.org). Also, blocking of TLR4 markedly increased the number of inflammatory cells in the BALF, including total white blood cells, lymphocytes, neutrophils, basophils, and eosinophils, but did not change the macrophage count (see Supplemental Table S2 at http:// ajp.amjpathol.org).

\section{Functional Blockade of TLR4 Activity Aggravates Silica-Induced Pulmonary Fibrosis}

To verify the broader significance of TLR4 deficiency on chronic inflammation and fibrosis after chemical-induced 
A

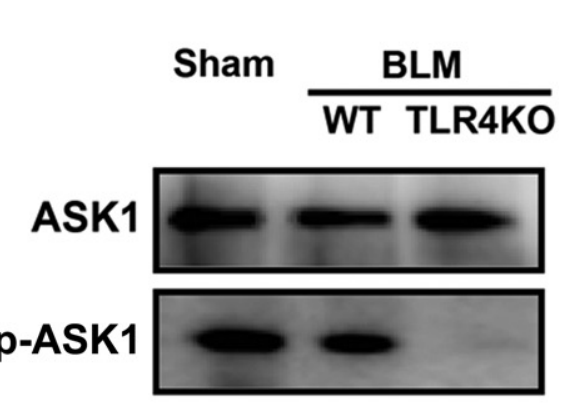

D

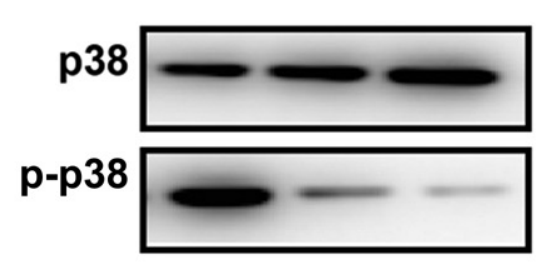

G

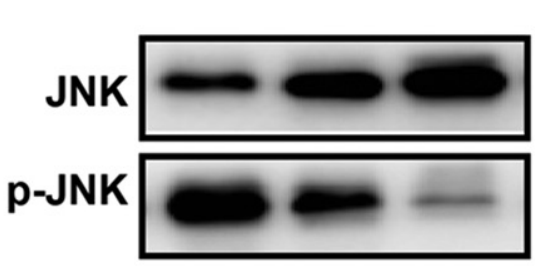

$E$

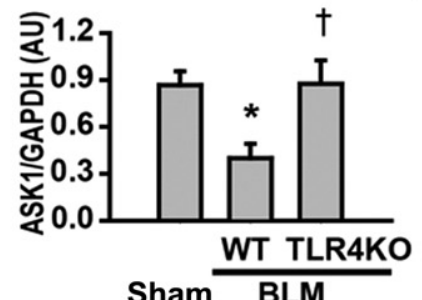

C

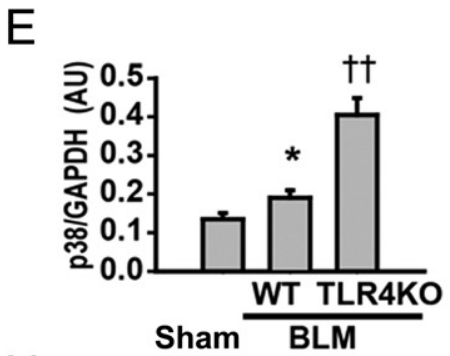

$\mathrm{H}$

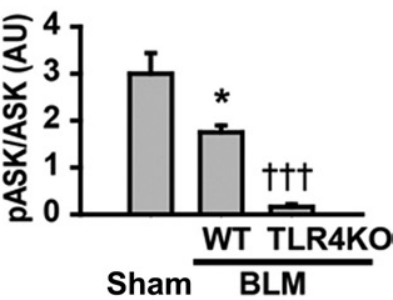

$\mathrm{F}$
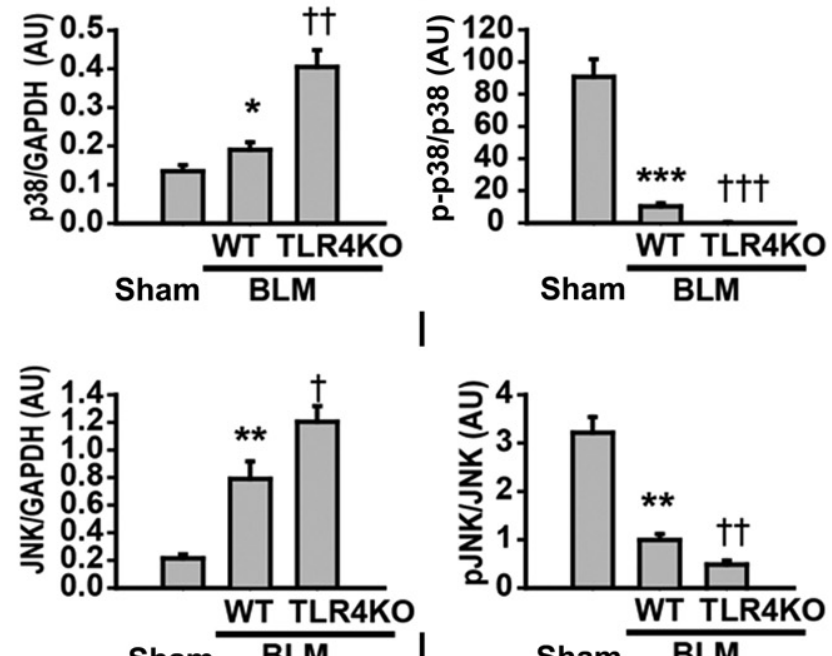

$J$

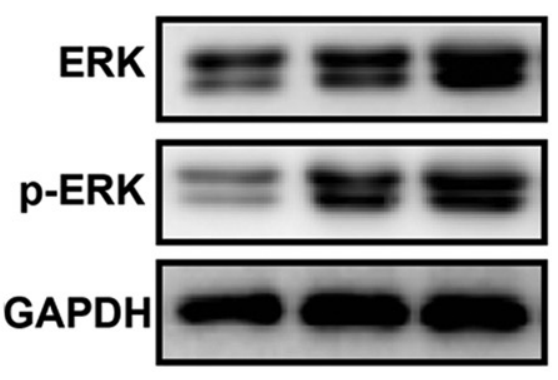

$\mathrm{K}$
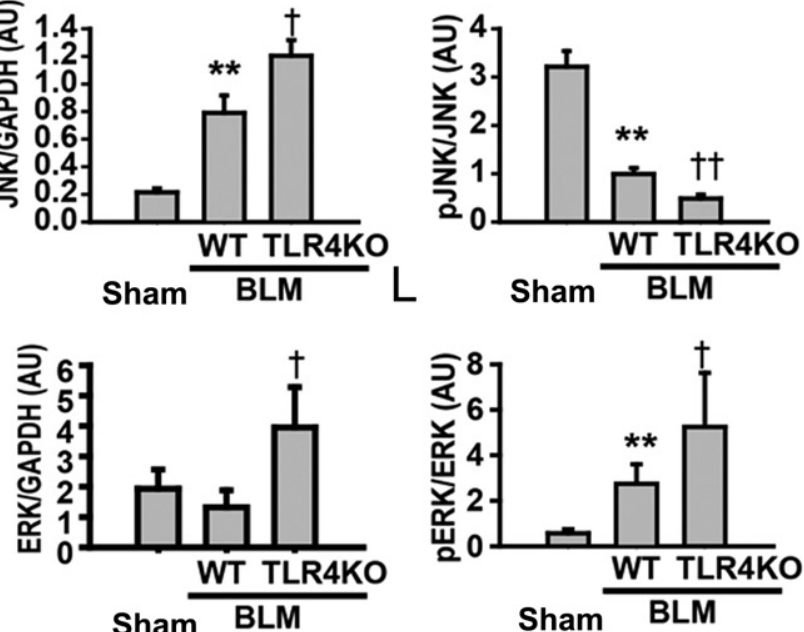

Sham BLM

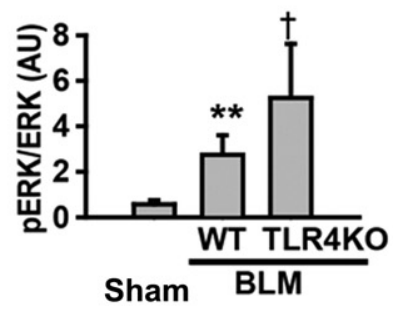

M

$\mathrm{N}$
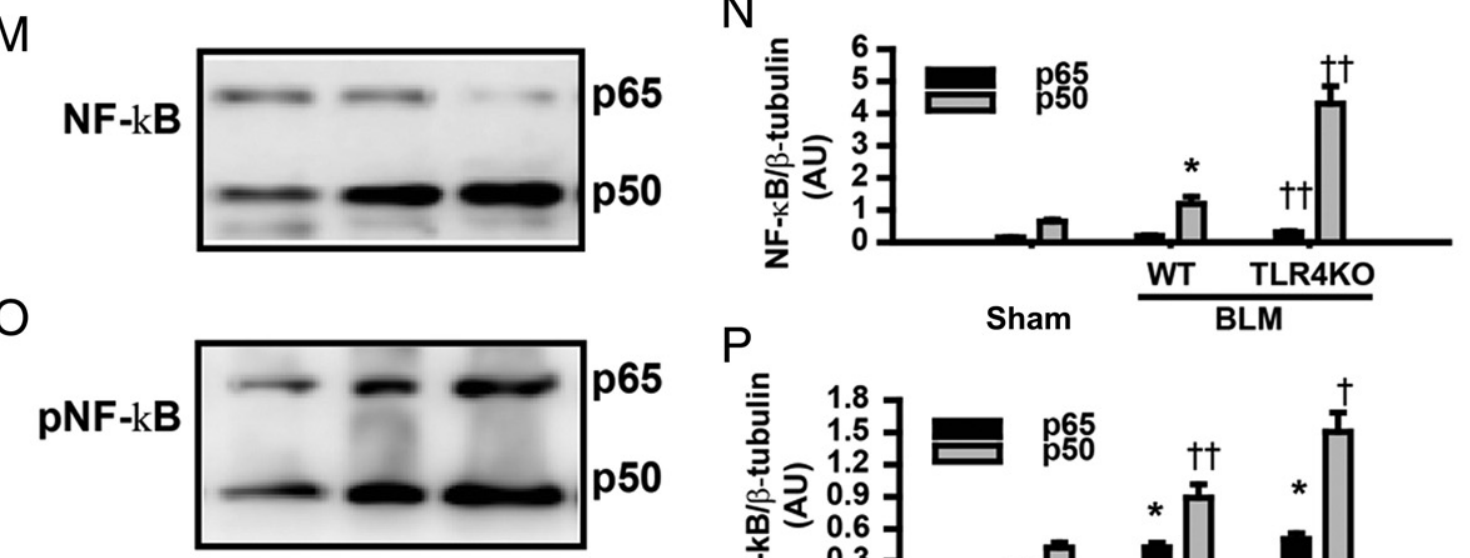

$\beta$-Tubulin

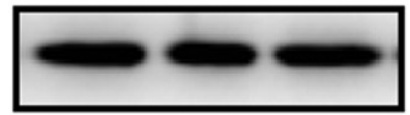

P

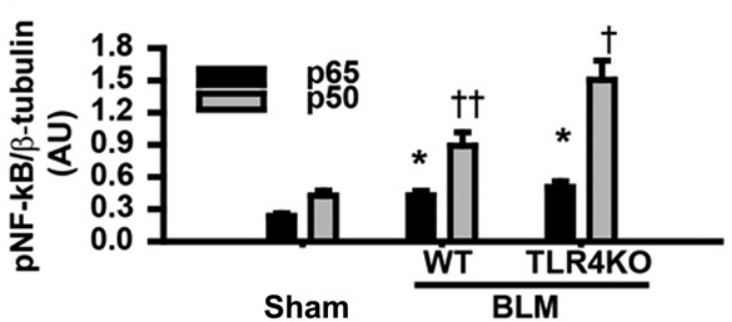

Figure 2. TLR4 deficiency inhibits ASK/p38 MAP kinase and activates ERK MAP kinase signaling pathways. Mice were treated as indicated in the legend of Figure 1. The lung tissues obtained were homogenized for Western blot to detect the expression and phosphorylation of ASK1 (A-C), p38 MAP kinase (D-F), JNK (G-I), ERK $(\mathbf{J}-\mathbf{L})$, and NF- $\kappa \mathrm{B}(\mathbf{M}-\mathbf{P})$. $\mathbf{A}, \mathbf{D}, \mathbf{G}, \mathbf{J}, \mathbf{M}$, and $\mathbf{O}$ show representative immunoblots. $\mathbf{B}, \mathbf{E}, \mathbf{H}, \mathbf{K}$, and $\mathbf{N}$ provide a summary of the ratio of indicated protein to glyceraldehyde-3-phosphate dehydrogenase (or $\beta$-tubulin for NF- $\kappa$ B). $\mathbf{C}, \mathbf{F}, \mathbf{I}, \mathbf{L}$, and $\mathbf{P}$ are summaries of the ratio of phosphoprotein to total protein from four independent experiments ( $n=6$ /group/experiment). ${ }^{*} P<0.05,{ }^{* *} P<0.01$, and ${ }^{* * * *} P<0.001$ compared with Sham mice; ${ }^{\dagger} P<0.05$, ${ }^{\dagger t} P<0.01$, and ${ }^{{ }^{t t}} P<0.001$ compared with bleomycin (BLM)-treated wild type (WT) mice. AU, arbitrary units; GADPH, glyceraldehyde-3-phosphate dehydrogenase; p, phosphorylation. 
A

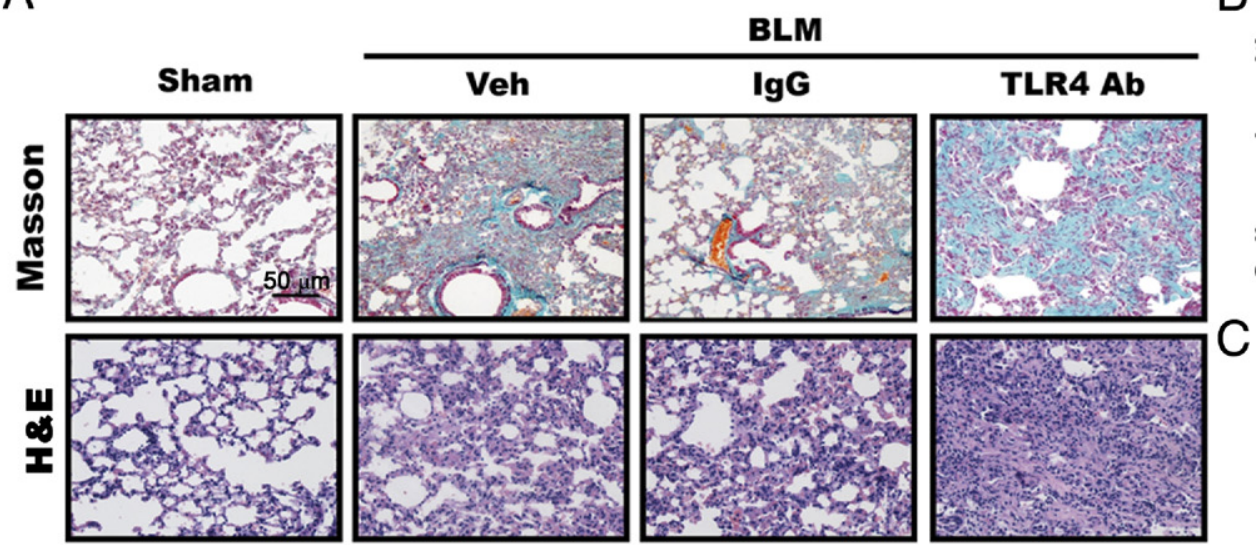

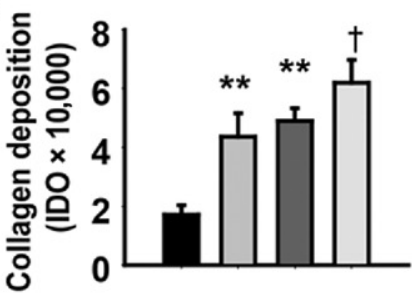

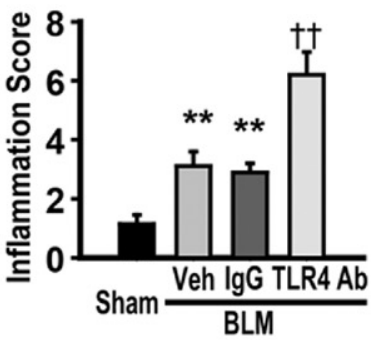

D

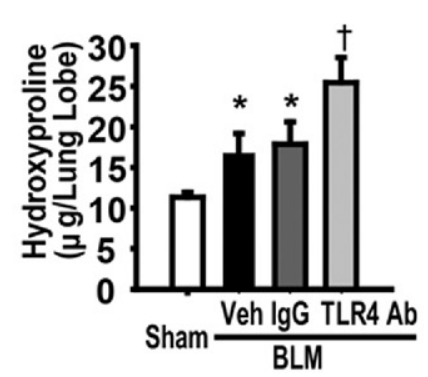

E

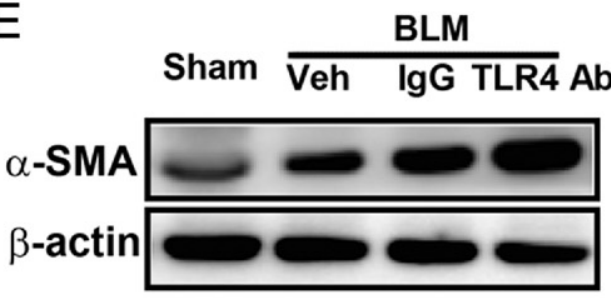

$F$
G

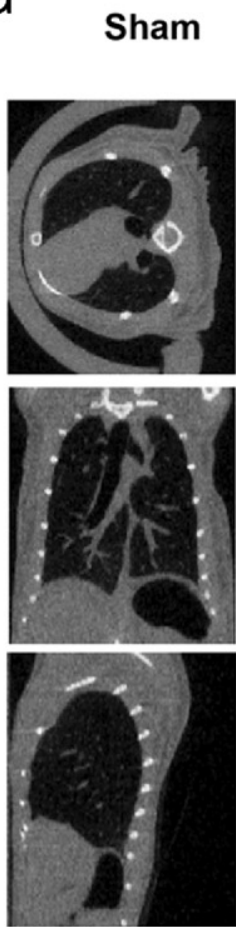

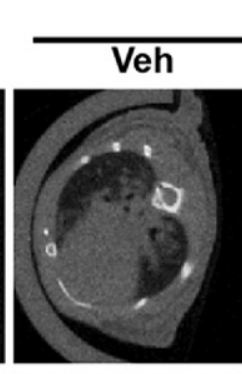
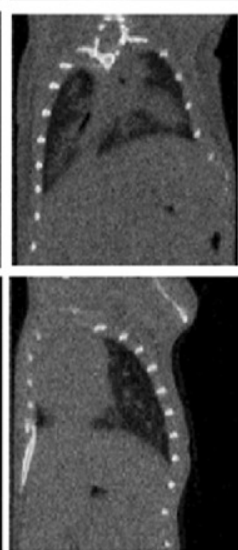

BLM
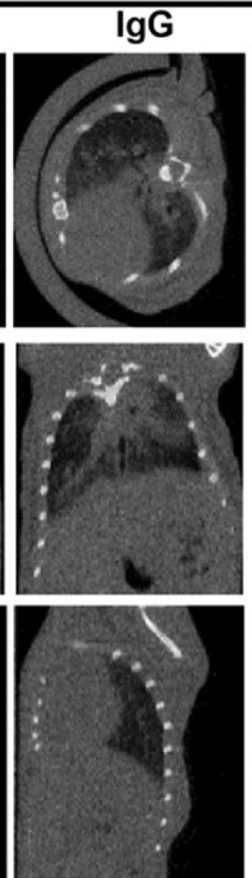
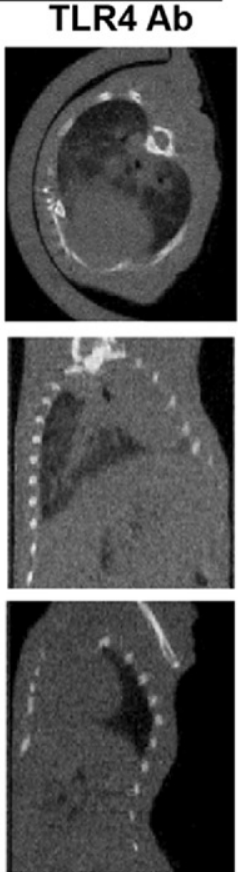

$\mathrm{H}$
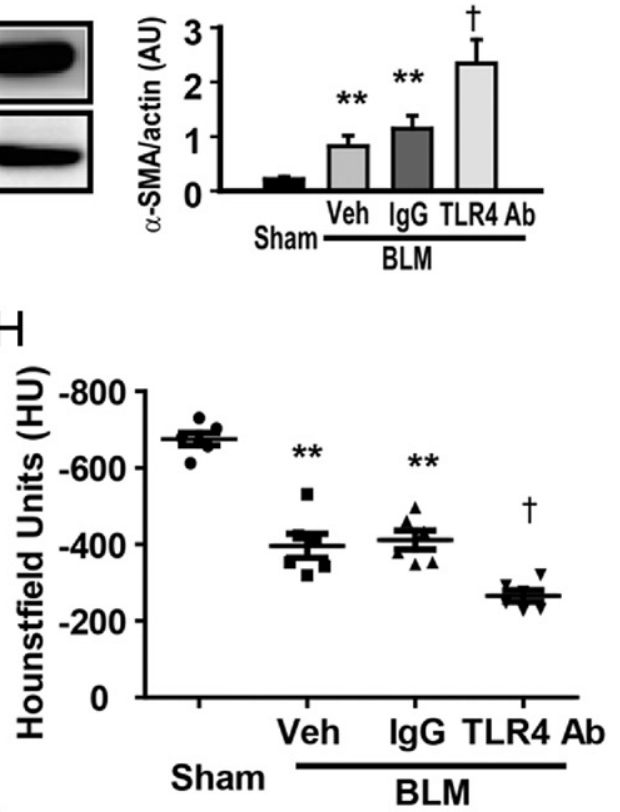

Figure 3. Neutralization of TLR4 aggravates bleomycin (BLM)-induced pulmonary inflammation and fibrosis. C57BL/6J mice were administered BLM ( 3 mg/kg) intratracheally, and a TLR4-neutralizing or isotype-matched antibody $(200 \mu \mathrm{g} / \mathrm{kg})$ was administered intravenously on day 10 and day 17 after BLM treatment. A-D: Blocking TLR4 enhanced the BLM-induced pulmonary inflammation and fibrosis. Data are representative images of Masson's trichrome and H\&E staining (A), summary of collagen deposition (B), summary of inflammation scores (C), and summary of hydroxyproline content (D). E and F: Blockade of TLR 4 enhanced the expression of $\alpha$-smooth muscle actin ( $\alpha$-SMA) in lungs. Data are representative immunoblots (E) and summary of $\alpha$-SMA expression (F). G: Representative micro-CT images. H: The summary of HU of mice. Data are presented as the mean \pm SD of three experiments $(n=12 /$ group/experiment). I: Blocking TLR4 increased the BLM-induced animal death. The survival rate was analyzed by the Kaplan-Meier method $(n=30) .{ }^{*} P<0.05$ and ${ }^{* *} P<0.01$ compared with Sham mice; ${ }^{\dagger} P<0.05$ and ${ }^{\dagger t} P<0.01$ compared with BLM-treated mice. Ab, antibody; IOD, integrated optical density. 
A

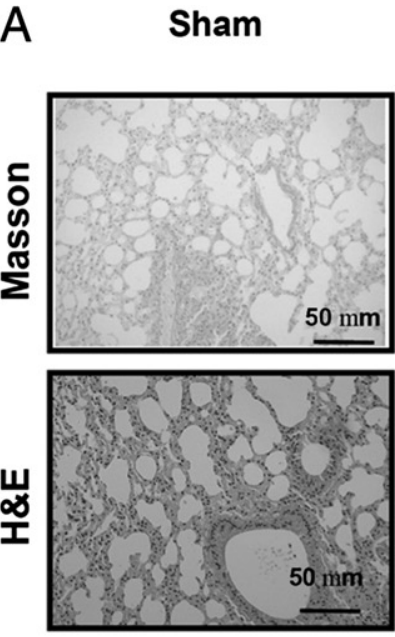

B

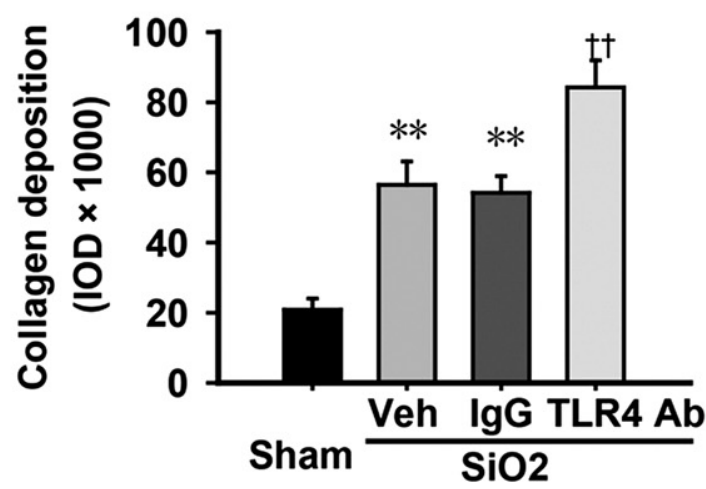

D
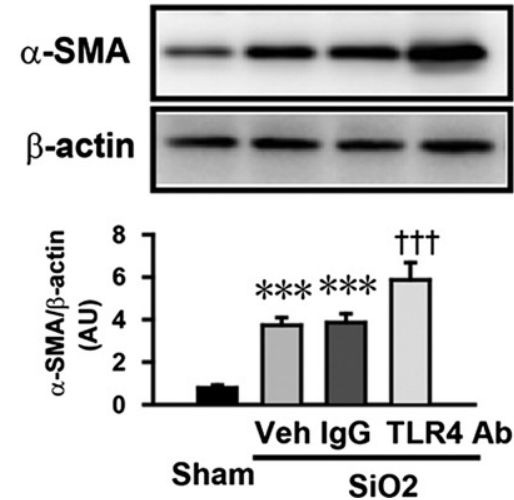

$\mathrm{SiO} 2$
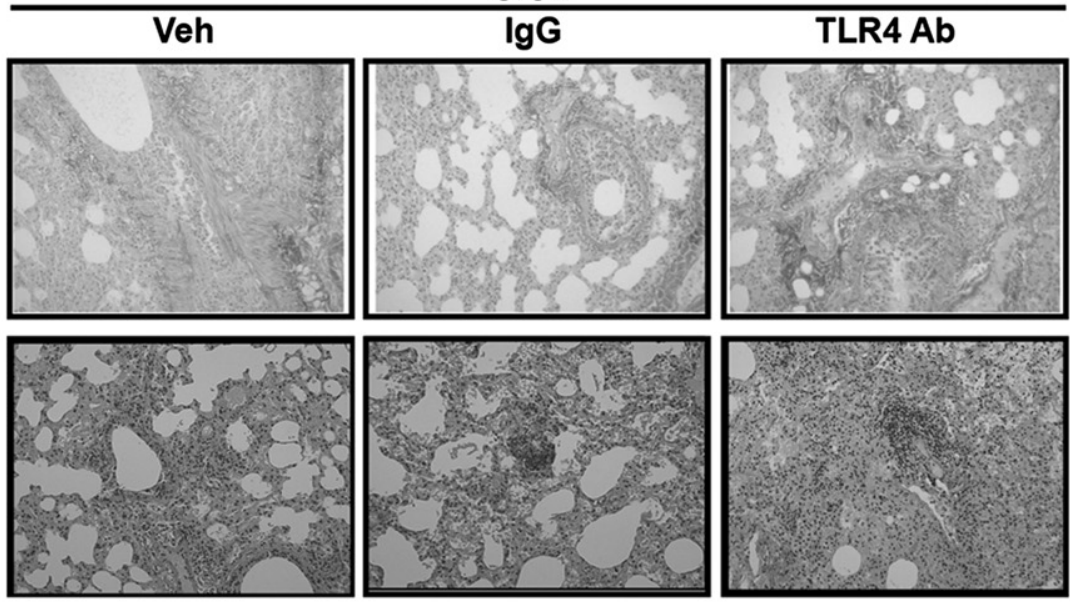

C

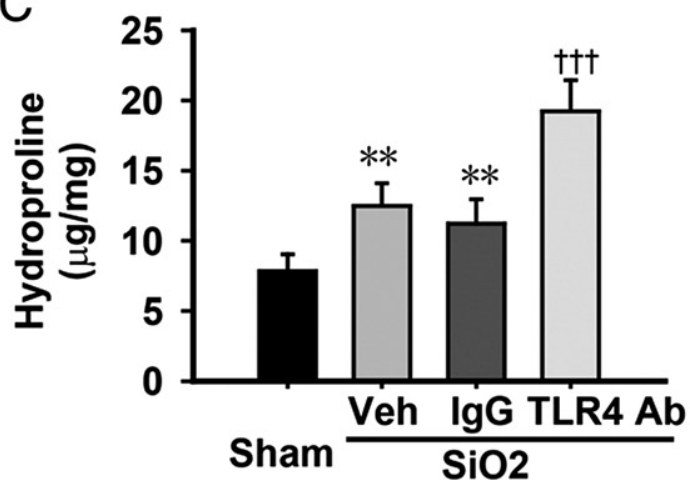

E

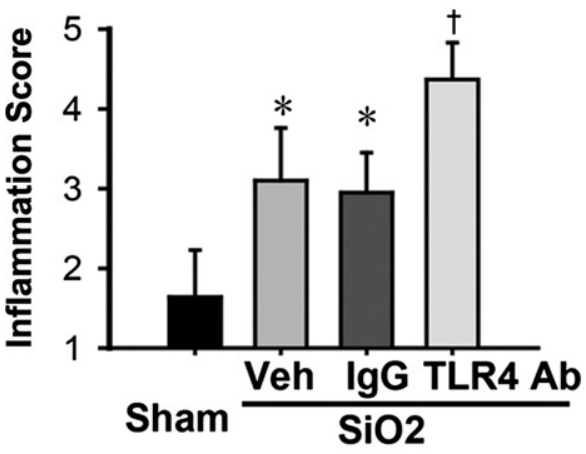

Figure 4. Functional blockade of TLR4 aggravates $\mathrm{SiO}_{2}$-induced pulmonary inflammation and fibrosis. $\mathrm{C} 57 \mathrm{BL} / 6 \mathrm{~J}$ mice were administered $\mathrm{SiO} \mathrm{O}_{2}$ (2.5 mg/mouse) intratracheally, and a TLR4-neutralizing or isotype-matched antibody $(200 \mu \mathrm{g} / \mathrm{kg})$ was administered intravenously once a week from day 14 after $\mathrm{SiO} \mathrm{O}_{2}$ treatment. A: Blocking TLR4 enhanced $\mathrm{SiO}_{2}$-induced pulmonary inflammation and fibrosis. Top panels: Representative images of Masson staining. Bottom panels: representative images of H\&E staining. B: Blockade of TLR 4 enhanced the deposition of collagen in lungs. The average IOD of collagen deposition was determined by Image-Pro Plus image analysis software in 10 randomly chosen regions per tissue sample at a magnification of $\times 200$. C: Blockade of TLR4 enhanced the content of hydroxyproline in lungs. D: Blockade of TLR 4 enhanced the expression of $\alpha$-smooth muscle actin ( $\alpha$-SMA) in lungs. E: Blocking TLR 4 increased the inflammation scores of lungs. Data are presented as the mean $\pm \mathrm{SD}$ of three experiments $\left(n=12 /\right.$ group/experiment). ${ }^{*} P<0.05$, ${ }^{* *} P<0.01$, and ${ }^{* * * *} P<0.001$ compared with Sham mice; ${ }^{\dagger} P<0.05,{ }^{+} P<0.01$ and ${ }^{\dagger+t} P<0.001$ compared with SiO2-treated mice. Ab, antibody; AU, arbitrary units; IOD, integrated optical density.

tissue injury, we generated a mouse model of silicainduced pulmonary fibrosis. Pathologic analysis revealed that silica administration resulted in the progressive development of pulmonary fibrotic nodules to larger silicosis nodules, slight inflammatory exudates in interstitial lung regions, vitreous degeneration, distortion of lung architecture, and collagen deposition on day 60 after silica administration (Figure 4A).
Blockade of TLR4 with neutralizing antibody significantly aggravated the degree of pulmonary inflammation and fibrosis (Figure 4, A and B), as evidenced by the increase in collagen deposition, enhancement of $\alpha$-SMA expression, and elevation of the inflammatory score in the lungs (Figure 4, B-E). In addition, TLR4 blockade not only reduced the $\mathrm{HU}$ values of the lungs (see Supplemental Figure S4, A and B at http://ajp.amjpathol.org) but also 
caused a further decline of lung function, as indicated by the reduction of Cchord and FRC values (see Supplemental Figure S4C at http://ajp.amjpathol.org).

\section{TLR4 Deficiency Inhibits BLM-Activated Autophagy Signaling and Autophagy- Associated Cell Death/Apoptosis in BLM-Injured Lung Tissue}

BLM causes production of ROS and activation of caspase 3 to induce tissue apoptosis and inflammation, which play important roles in the pathogenesis of pulmonary fibrosis. ${ }^{29}$ Thus the regulatory effects of TLR4 deficiency on ROS generation and tissue apoptosis in lungs were investigated. TLR4 ${ }^{-1-}$ mice showed significant accumulation of ROS and inhibition of the active form of caspase 3 in the lungs (see Supplemental Figure S5, A and $\mathrm{B}$ at http://ajp.amjpathol.org). In addition, TLR4 deficiency caused reductions in the numbers of early apoptotic cells (annexin $\mathrm{V}^{+} \mathrm{PI}^{-}$cells), apoptotic cells (annexin $\mathrm{V}^{+} \mathrm{PI}^{+}$cells), and dead cells/late apoptotic cells (annexin $\mathrm{V}^{-} \mathrm{PI}^{+}$cells) in BLM-injured lung tissue (see Supplemental Figure S5C at http://ajp.amjpathol.org).

To further investigate the mechanism of TLR4 deficiency on cell death, we analyzed the types of apoptosis or autophagy-associated cell death, as described previously. ${ }^{27}$ TLR4 deficiency significantly reduced the number of autophagy-associated dead cells (as quantified by both LC3 dots and TUNEL staining) in lung tissue (Figure $5 A$ ). These results indicate that the aggravation of pulmonary inflammation and fibrosis in TLR4 ${ }^{-1-}$ mice is associated with an attenuation of autophagy-associated cell death.

To confirm the effects of TLR4 deficiency on autophagy in injured lungs, we detected the expression and activity of autophagy-associated signaling molecules. TLR4 deficiency significantly inhibited the conversion of LC3B I to LC3B II and down-regulated the expression of both Beclin1 and PI3K3C (Figure 5, B-J). Consistent with these findings, TLR4 deficiency promoted the expression and phosphorylation of AKT and mTOR (Figure 5, B-J). Similarly, TLR4 deficiency not only inhibited the formation of autophagosomes (represented as the co-expression of LC3 and LAMP1, Figure 6, A and B) but also resulted in decreased numbers of autophagosomes in lung tissue (Figure 6, C and D). Additionally, TLR4 deficiency inhibited autophagy-associated collagen degradation, resulting in enhanced collagen deposition (Figure 6E).

Indeed, in vitro experiments indicated that TLR4 activation enhanced, whereas TLR4 blockade attenuated, the degradation of collagen in epithelial cells (JHU-1) that "eat" FITC-labeled collagen (Figure 6F). Inhibition of autophagy with 3-MA countered the effects of TLR4 blockade on degradation of collagen in $\mathrm{JHU}-1$ cells (Figure $6 F)$. These results indicate that TLR4 deficiency results in the inactivation of autophagy, which contributes to the deposition of collagen in fibrotic tissue.

\section{Activation of TLR4 Attenuates the BLM-Induced Pulmonary Fibrosis via Activation of Autophagy}

To confirm the crucial protective role of TLR4 activity in the resolution of inflammation and fibrosis after acute lung injury, we conducted additional animal experiments in which we applied a TLR4 agonist (Ec-LPS) as a therapeutic strategy against established pulmonary fibrosis. We found that TLR4 activation inhibited inflammation, collagen deposition, hydroxyproline accumulation, and $\alpha$-SMA expression (Figure 7, A-C) in BLM-injured lungs, leading to improvement of lung function (Figure 7D; also see Supplemental Figure S6 at http://ajp.amjpathol.org) and reduction of BLM-caused animal death (Figure 7E). TLR4 activation also significantly enhanced the lung density and $\mathrm{HU}$ value of BLM-treated mice compared with mice treated without a TLR4 agonist (data not shown).

In contrast to TLR4 deficiency, the TLR4 agonist EcLPS promoted autophagic activity in lung tissue, causing a significant increase in the conversion of LC3B I to LC3B $\mathrm{II}$ and the expression of Beclin1 and the active form of caspase 3 (Figure 7, F-I). Furthermore, Ec-LPS treatment markedly increased the number of autophagosomes in the lungs (Figure 7J). Additionally, Ec-LPS enhanced the level of autophagy-associated collagen degradation, represented as an increase in the number of LC3-positive and collagen-positive cells (red arrows), and resulted in a reduction in the number of collagen dots (blue arrows) (Figure 7L).

Activation of TLR4 also significantly lowered the infiltration of total white blood cells, lymphocytes, neutrophils, and basophils in BALF but did not change the infiltration of eosinophils and macrophages (see Supplemental Table S3 at http://ajp.amjpathol.org). These effects on immune cell numbers were associated with significantly enhanced expression of the Th1 cytokine IFN- $\gamma$ and reduced expression of the Th2 cytokines IL-4, IL-5, IL-10, IL-13, and TGF- $\beta 1$ (see Supplemental Figure S7 at http://ajp.amjpathol.org).

\section{Regulating Autophagy Reverses the Effects of TLR4 on BLM-Induced Pulmonary Fibrosis}

To confirm the role of autophagy in TLR4-regulated pulmonary fibrosis after BLM-induced acute lung injury, we examined the effects of autophagy stimulator rapamycin on TLR4 blockade-aggravated fibrosis and autophagy inhibitor 3-MA on Ec-LPS-attenuated fibrosis (Figure $8 \mathrm{~F}$ ). In agreement with the report by Kim et $\mathrm{al},{ }^{30}$ rapamycin countered the effect of TLR4 blockade by significantly activating autophagy via enhancing LC3 conversion and expression of Beclin1 (Figure 8A), whereas 3-MA effectively reversed Ec-LPS-stimulated autophagy (Figure 8A). Activation of autophagy by rapamycin also significantly rescued the exacerbation of the fibrotic response caused by TLR4 neutralizing antibody, as indicated by reductions in collagen deposition, hydroxyproline content, and $\alpha$-SMA expression (Figure 8, B-E). 
A
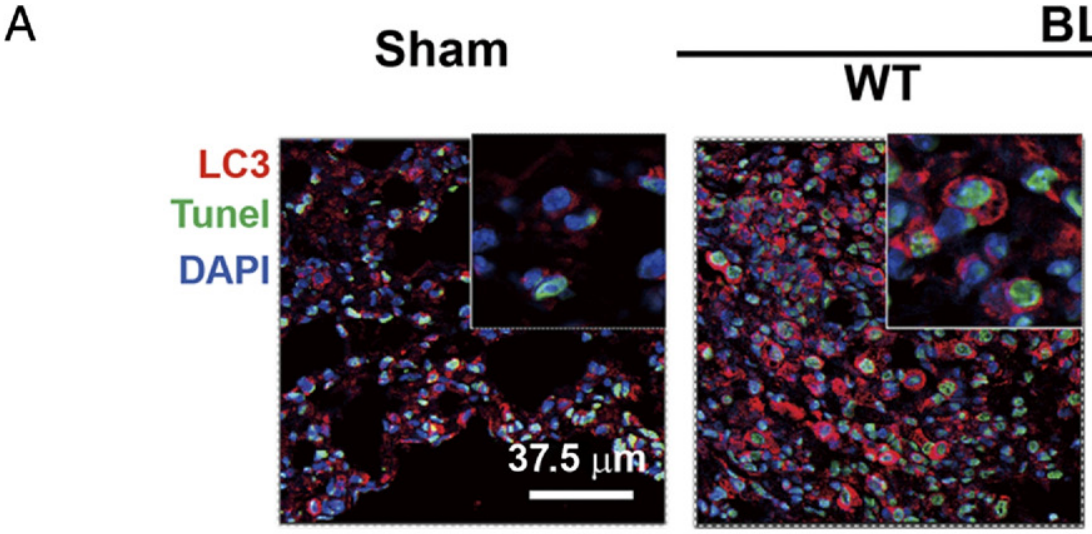

BLM

TLR4KO

B

BLM
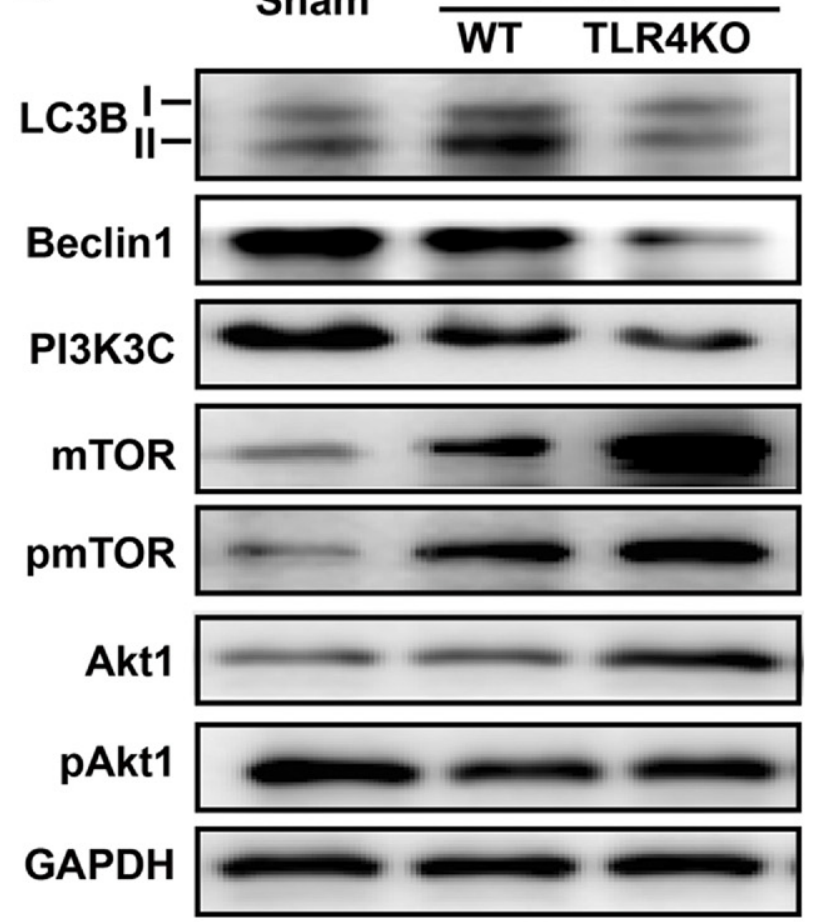

Figure 5. TLR 4 deficiency attenuates autophagy-associated apoptosis in the bleomycin (BLM)-injured lung tissues. Mice were treated as indicated in the legend of Figure 1. The lungs obtained were fixed and processed into tissue sections for detection of autophagy by immunofluorescence microscopy. A: TLR4 deficiency reduced the number of LC3-positive and TUNEL-positive cells. Data are representative images of three independent experiments $(n=$ 6/group/experiment). Red, LC3 dots; green, TUNEL-positive cells; blue, DAPI-labeled nuclei of the same fields. Scale bar: top bar of each group = $7.5 \mu \mathrm{m}$; bottom bar of each group $=37.5 \mu \mathrm{m}$. B-J: TLR4 deficiency regulated the expression of autophagy-associated proteins in fibrotic lung tissue. B: Representative immunoblots. C-J: Summary for the ratios of indicated protein to glyceraldehyde-3-phosphate dehydrogenase or phosphoprotein to total protein, including LC3 I (C), LC3 II/LC3 I (D), Beclin1 $(\mathbf{E})$, PI3K3C (F), mammalian target of rapamycin (mTOR) (G), phosphor-TOR/ mTOR $(\mathbf{H})$, Akt (I), and phosphor-Akt/Akt (J). Data are representative results of four experiments ( $n=6$ /group/experiment). ${ }^{*} P<0.05$ and ${ }^{* *} P<0.01$ compared with Sham mice; ${ }^{\dagger} P<0.05$ and ${ }^{H} P<0.01$ compared with BLMtreated mice. AU, arbitrary units; GADPH, glyceraldehyde-3-phosphate dehydrogenase; p-Akt1, phosphorylated Akt1; pm-TOR, phosphorylated mTOR; WT, wild type.
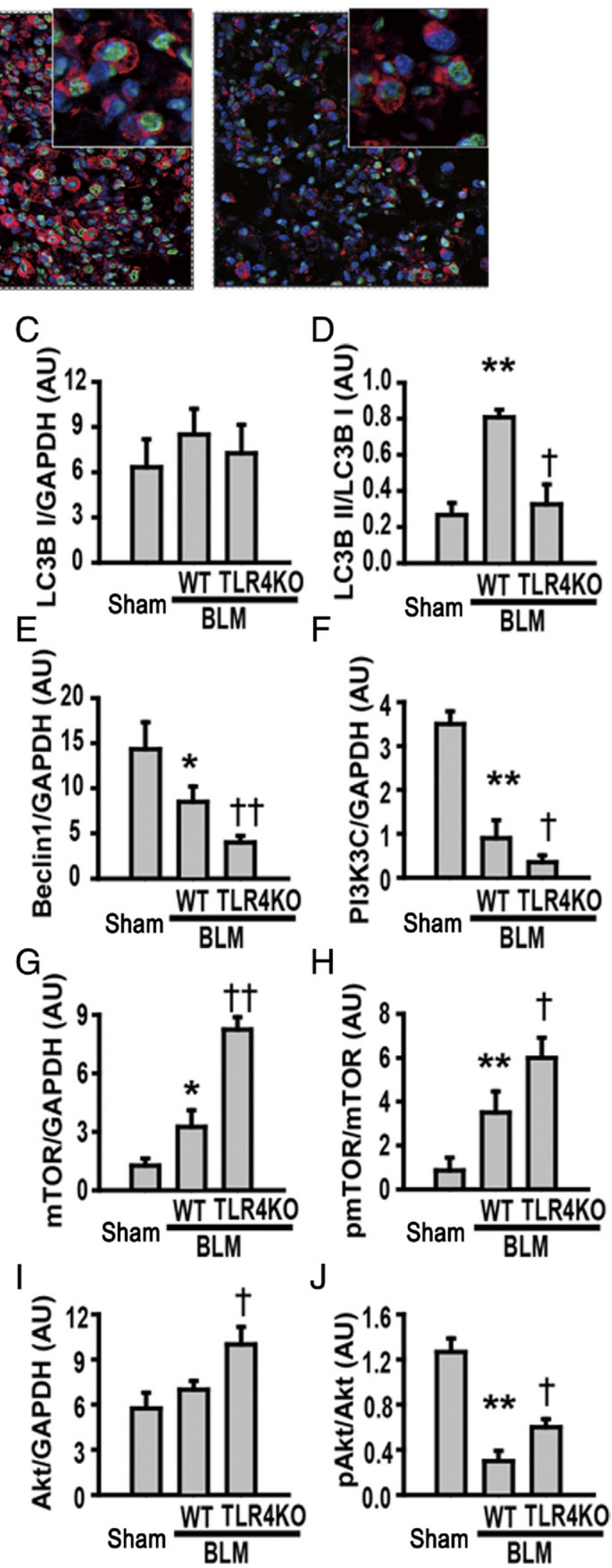
$\mathrm{H}$

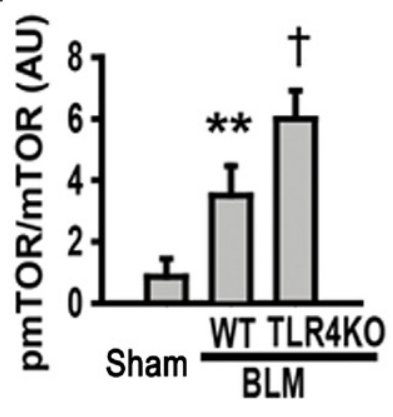
$\mathrm{J}$

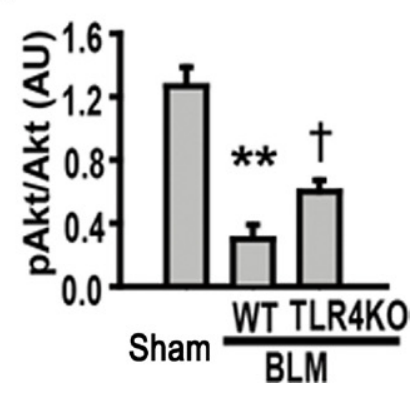



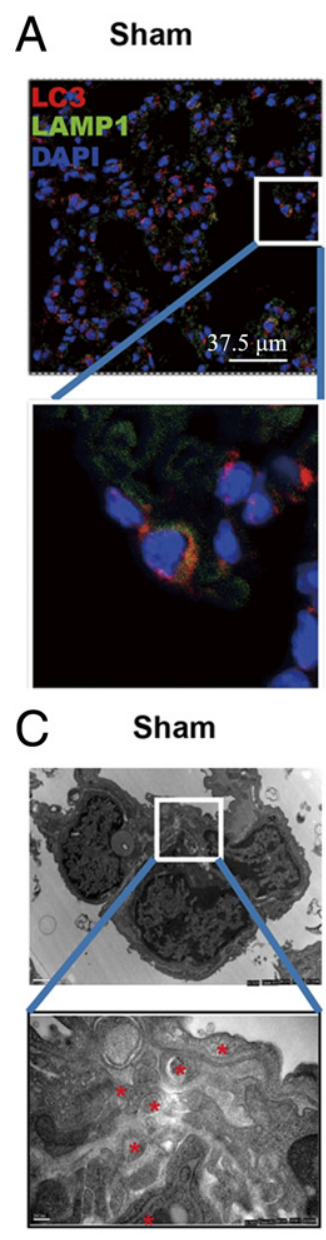

E

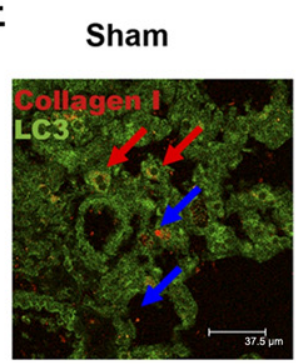

BLM
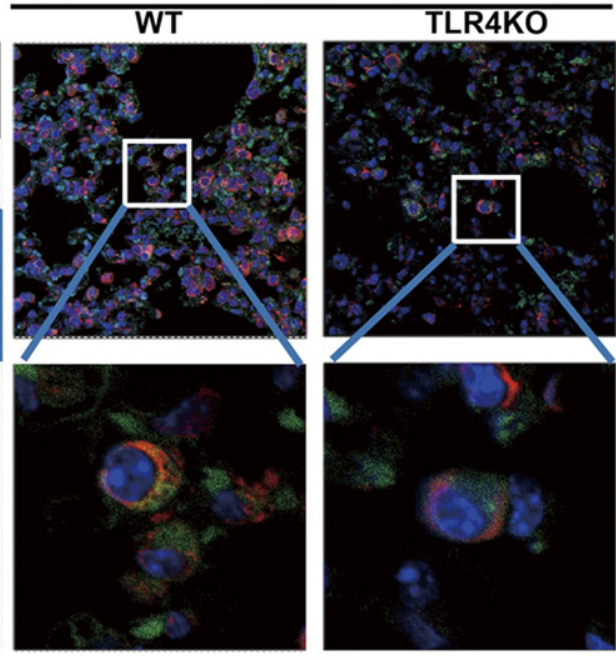

BLM
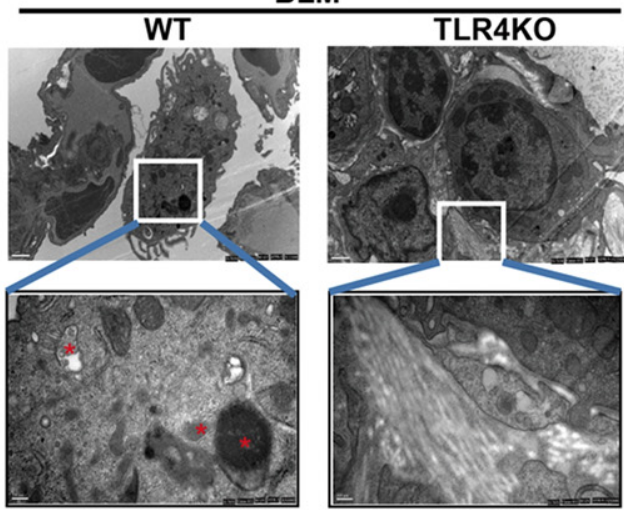

BLM

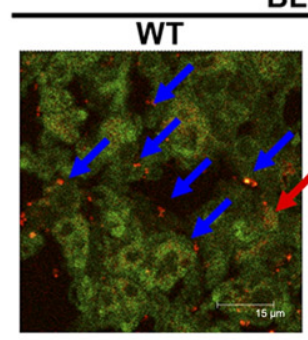

B

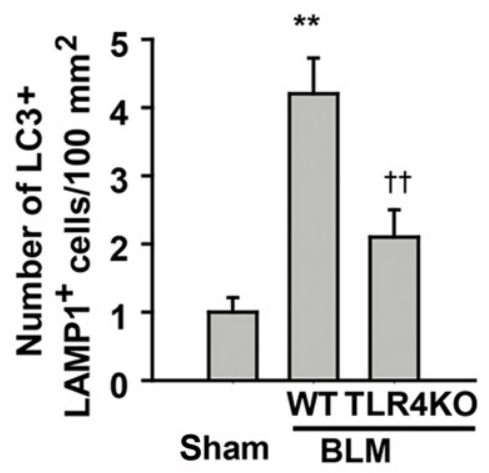

D
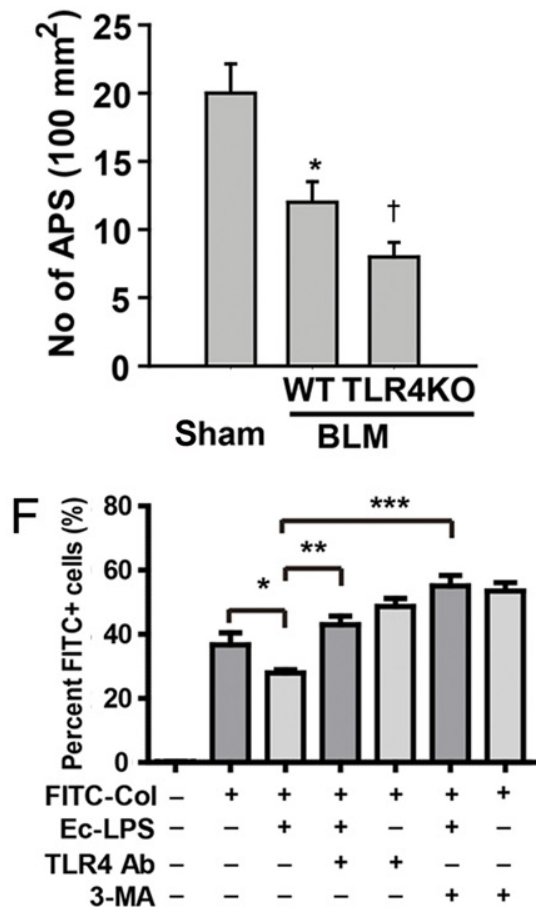

Figure 6. TLR 4 deficiency reduces autophagosome number and autophagy-associated collagen degradation in fibrotic lungs. The animals were treated as indicated in the legend of Figure 1. The lung tissues obtained were fixed and processed into tissue sections for detection of autophagosomes by immunofluorescence microscopy and electron microscopy and for measurement of autophagy-associated collagen degradation by immunofluorescence microscopy or flow cytometry. A: Representative confocal images. Green = LAMP1-positive cells; red = LC3 dots; blue = DAPI-stained nuclei. B: Summary of LC3-positive and LAMP1-positive cells in the lungs. C: Representative electron microscopic images. Red asterisks indicate the autophagosomes in the lungs. Top images: $\times 5000$; bottom images: $\times 12,000$. D: Summary of the number of autophagosomes per $100 \mu \mathrm{m}^{2}$ lung tissue. Data are representative results of three independent experiments $(n=6 /$ group/experiment $)$. E: TLR4 deficiency inhibited autophagy-associated collagen degradation in lungs. Green $=$ LC3; red $=$ collagen. Blue arrows indicate deposited collagen; red arrows indicate autophagy-associated collagen degradation. Scale bar $=37.5 \mu \mathrm{m}$. F: Activation of TLR4 promoted the degradation of collagen via enhancement of autophagy. The FITC-labeled collagen I was added into the media of JHU-1 cells treated with Ec-LPS (100 ng/mL), TLR4 $\mathrm{Ab}(10 \mu \mathrm{g} / \mathrm{mL})$, or 3-methyladenine (3-MA) $(2 \mathrm{mmol} / \mathrm{L})$ as indicated in the figure. Eight hours later, the cells were collected and analyzed by flow cytometry. Data are presented as the mean \pm SD of three independent experiments. ${ }^{*} P<0.05,{ }^{* * *} P<0.01,{ }^{* * * *} P<0.001$ compared with Sham mice; ${ }^{\dagger} P<0.05$, ${ }^{t \dagger} P<0.01$, ${ }^{{ }^{+\dagger} P}<0.001$ compared with bleomycin (BLM)-treated mice. Ab, antibody; APS, autophagosomes; Ec-LPS, purified from Escherichia coli 0111: B4 strain; WT, wild type.

In contrast, inhibition of autophagy by 3-MA reversed EcLPS-attenuated pulmonary fibrosis, as reflected by increased collagen deposition, hydroxyproline content, and $\alpha$-SMA expression (Figure 8, B-E). Therefore activation of autophagy improved the survival rate of mice subjected to TLR4 antibody and BLM, whereas inhibition of autophagy negated the reduction in animal death brought about by Ec-LPS treatment (Figure $8 \mathrm{~F}$ ). These results indicate that autophagy is critical in TLR4-regulated pulmonary fibrosis and animal death after acute lung injury (Figure 9). 
A
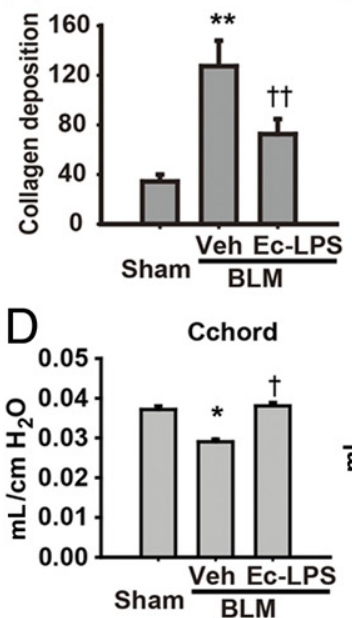

$\mathrm{F}$
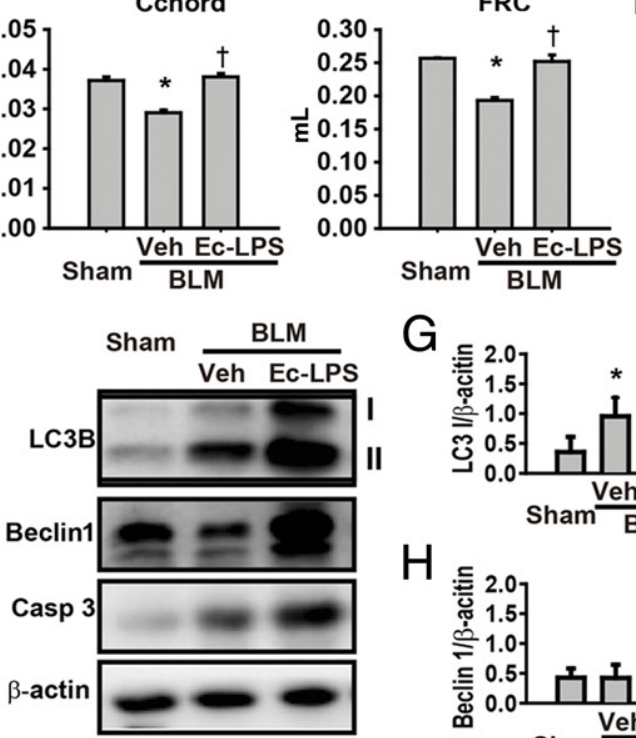

$\mathrm{G}$
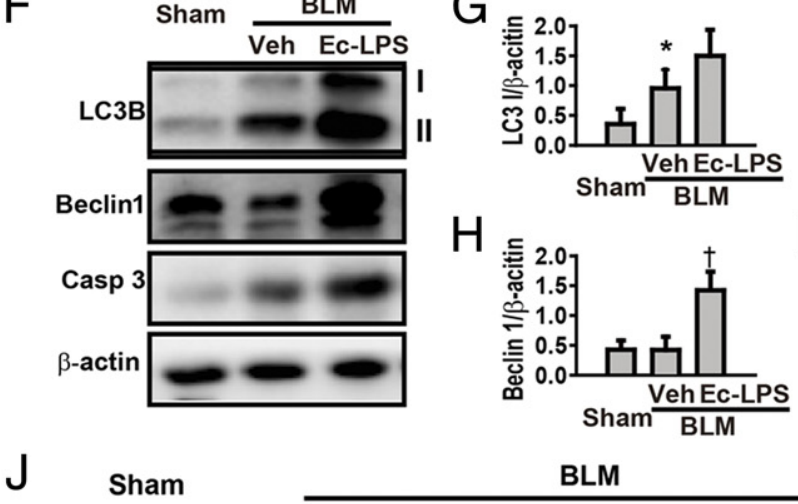

BLM

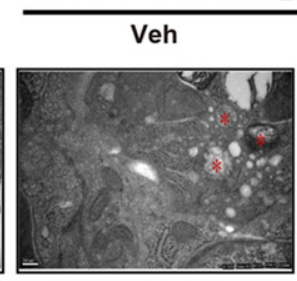

Sham

$\mathrm{L}$
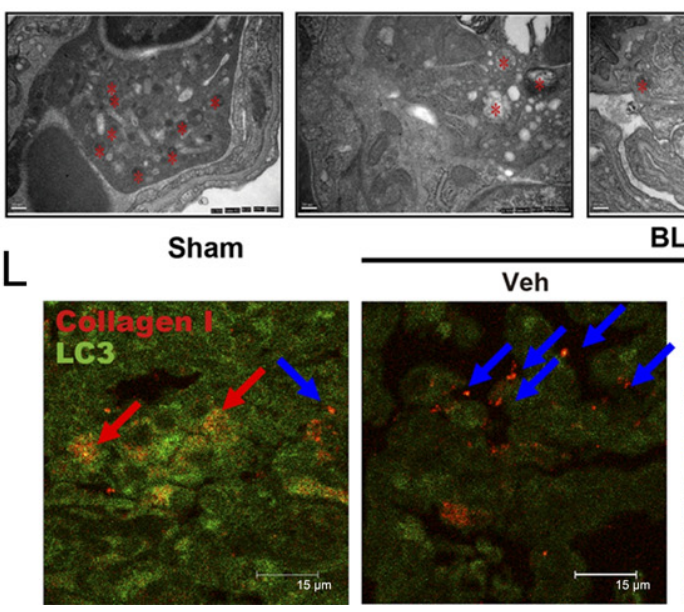

E
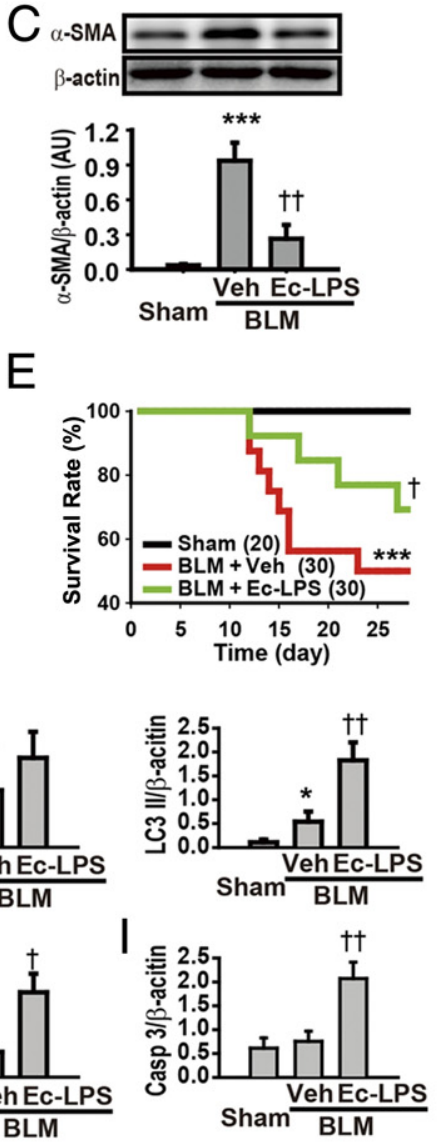

(1)

Figure 7. TLR 4 agonist activates autophagy and promotes resolution of pulmonary inflammation and fibrosis. Bleomycin (BLM)-induced pulmonary fibrosis was generated and the mice were treated with or without the TLR4 agonist purified from Escherichia coli 0111: B4 strain (Ec-LPS) $(10 \mathrm{mg} / \mathrm{kg} /$ day) from day 10 to day 17 after BLM administration. A-C: Ec-LPS attenuated established pulmonary fibrosis. Data are a summary of collagen deposition (A), summary of hydroxyproline content (B), and the expression of $\alpha$-SMA (C). D: Ec-LPS improved lung function, as indicated by an increase in lung compliance (Cchord) (left panel) and functional residual capacity (FRC) (right panel). Data are summarized from two independent experiments ( $n=$ 12/group/experiment). E: Ec-LPS improved the survival of BLM-treated mice. The survival rate was analyzed by the Kaplan-Meier method. F-I: Ec-LPS activated autophagy in BLM-injured lung tissues. The expression of autophagy-associated proteins LC3B, Beclin1, and active caspase 3 (Casp 3) was analyzed by Western blot. Data are representative immunoblots of three independent experiments (F) and the ratio of specific protein/ $\beta$-actin, including LC3 I, LC3 II, Beclin1, and active caspase 3 ( $n=6 /$ group/experiment) (G-I). $\mathbf{J}$ and $\mathbf{K}$ : Ec-LPS increased the number of autophagosomes in lungs. Representative electron micrographs show autophagosomes in the lungs $\times 12,000 \quad(\mathbf{J})$. Right panel indicates the number of autophagosomes per $100 \mu \mathrm{m}^{2}$ in the lungs. Data are representative of two independent experiments ( $n=6 /$ group/experiment). The summary of autophagosomes was calculated as indicated in Materials and Methods (K). L: Ec-LPS promoted autophagy-associated collagen degradation in lungs. Scale bars $=15$ $\mu \mathrm{m}$. Green, LC3; red, collagen. Blue arrows indicate deposited collagen; red arrows indicate autophagy-associated collagen degradation. Data are representative of two independent experiments ( $n=6$ /group/experiment). ${ }^{*} P<0.05,{ }^{* * *} P<0.01$ and ${ }^{* * * *} P<0.001$ compared with Sham mice; ${ }^{\dagger} P<0.05,{ }^{\dagger} P<0.01$, and ${ }^{\dagger+t} P<0.001 \mathrm{com}-$ pared with BLM-treated mice. $\alpha$-SMA, $\alpha$-smooth muscle actin; APS, autophagosomes; AU, arbitrary units.

\section{Discussion}

In this study, we provided compelling evidence that TLR4 activity plays a critical protective role in the proresolution of acute and chronic inflammation and pulmonary fibrosis after acute and chronic lung injury induced by chemical agents. We found that genetic deletion or pharmacologic inhibition of TLR4 activity impairs the resolution of inflammation and fibrosis in lungs that have undergone BLM and silica insults through inducing an immunosuppressive re- sponse and suppressive autophagic activity, which drives pulmonary structural remodeling and dysfunction. However the activation of TLR4 skews the immunosuppressive response toward a Th1-predominant immune response and activates and maintains the autophagy-mediated degradation of collagen and autophagy-associated cell death, which results in the resolution of inflammation and established pulmonary fibrosis, the improvement of lung function, and the reduction of animal death after acute lung injury. 
A

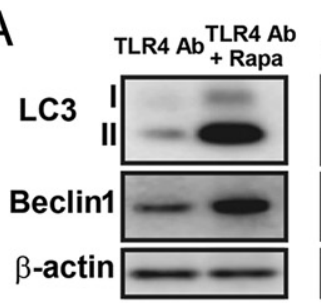

C
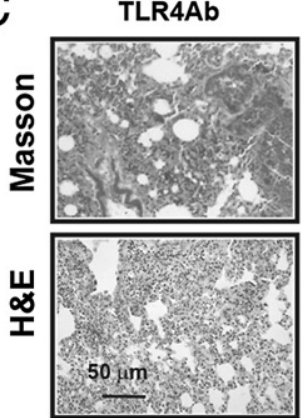

D

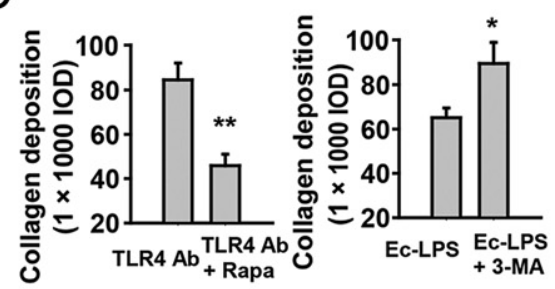

$\mathrm{F}$
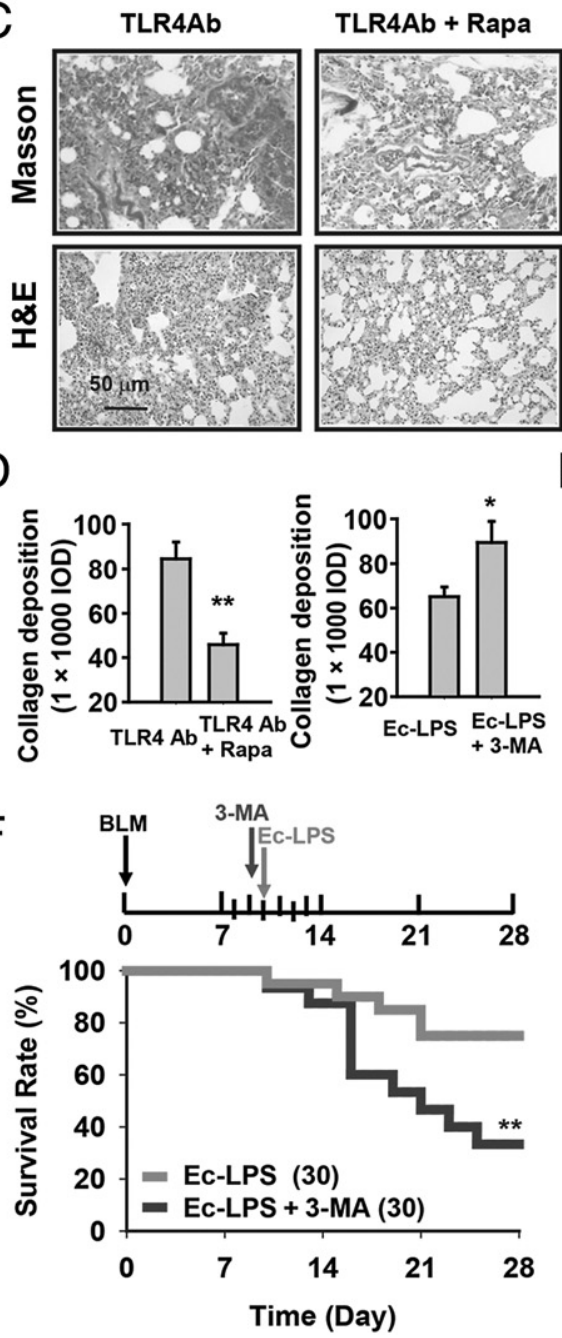

B

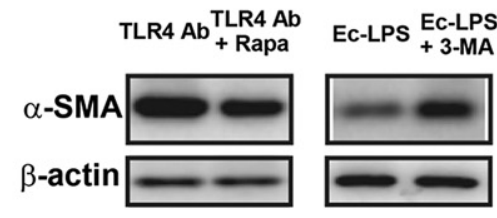

Ec-LPS
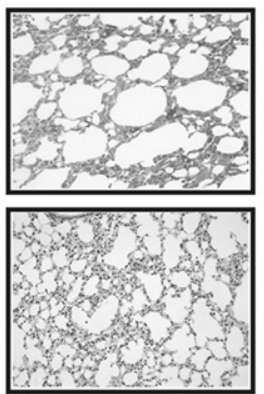

E
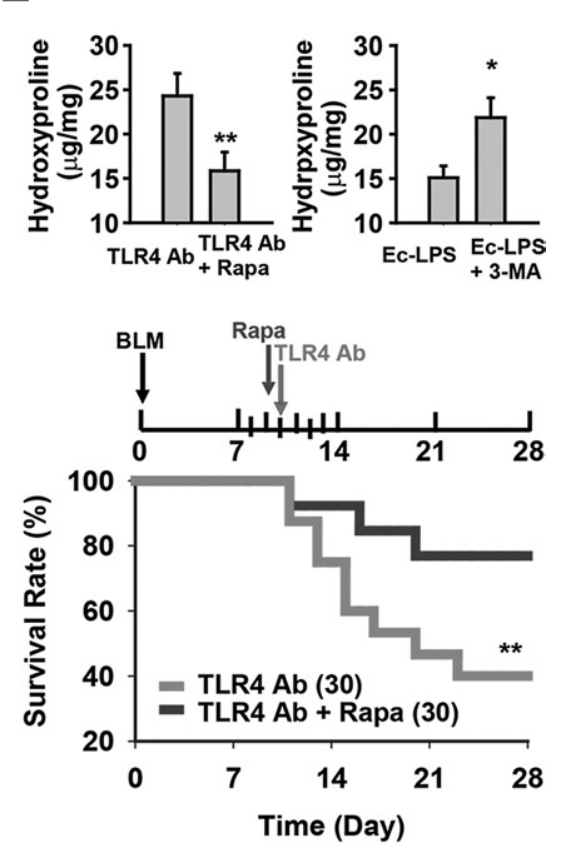

Figure 8. Changing autophagic activity regulates TLR4-mediated resolution of pulmonary in flammation and fibrosis. A and B: Representative immunoblots of the autophagic proteins LC3 and Beclin $1(\mathbf{A})$ and $\alpha$-smooth muscle actin ( $\alpha$-SMA) expression (B) were from three independent experiments. C-E: Autophagy modulators regulated the bleomycin (BLM)-induced pulmonary inflammation and fibrosis. Data were representative images of Masson's trichrome (top panels) and H\&E staining (bottom panels) of lung sections (C), summary of collagen deposition (D), and summary of hydroxyproline content (E). Data are presented as the mean $\pm \mathrm{SD}$ of two independent experiments ( $n=6 /$ group/experiment). F: Schematic diagram of the administration protocol and survival curves of mice. Pulmonary fibrosis was induced by BLM and the mice were treated as described in the Materials and Methods section. The survival rate was analyzed by the Kaplan-Meier method ( $n=15$ / group). ${ }^{*} P<0.05,{ }^{* *} P<0.01$. Ab, antibody Ec-LPS, purified from Escherichia coli 0111: B4 strain; 3-MA, 3-methyladenine; IOD, integrated optical density; Rapa, rapamycin.
These results not only highlight activation of TLR4 signaling as a promising strategy for the development of therapeutic agents against fibroproliferative diseases but also provide an explanation for the failure of immunosuppressive agents in the treatment of these diseases. Indeed, our studies support the assertion that chronic inflammation and tissue fibrosis are due to the failure of resolution of acute inflammation in response to infection, tissue injury, chemical agents, or stress and that regulating endogenous biochemical pathways such as TLR4 signaling and autophagic activity during defense reactions can counterregulate inflammation and promote inflammation resolution. ${ }^{31,32}$

There are "contradictory" observations on the role of TLR4 activity in the regulation of inflammation and tissue fibrosis in a diversity of tissue injury models. On one hand, various lines of evidence indicate that basal TLR4 activity plays a critical role in maintaining constitutive lung integrity and preventing chronic inflammation and tissue fibrosis. For example, the TLR4-induced Th1 response is attenuated in airway cells in cystic fibrosis, whereas TLR4 deficiency enhances the death of mice with cystic fibrosis. ${ }^{33,34}$ Also, TLR4 activity is required for clearing invasive pathogens and dead cells/debris to resolve the inflammation of pneumonic tularemia. ${ }^{35} \mathrm{In}$ deed, TLR4 activation promotes the self-defense of epithelium and protects mice from acute lung injury through TLR4-dependent basal activation of NF- $\kappa \mathrm{B},{ }^{36,37}$ whereas TLR4 deficiency increases the inflammatory response elicited by low-molecular-weight hyaluronic acid in the 


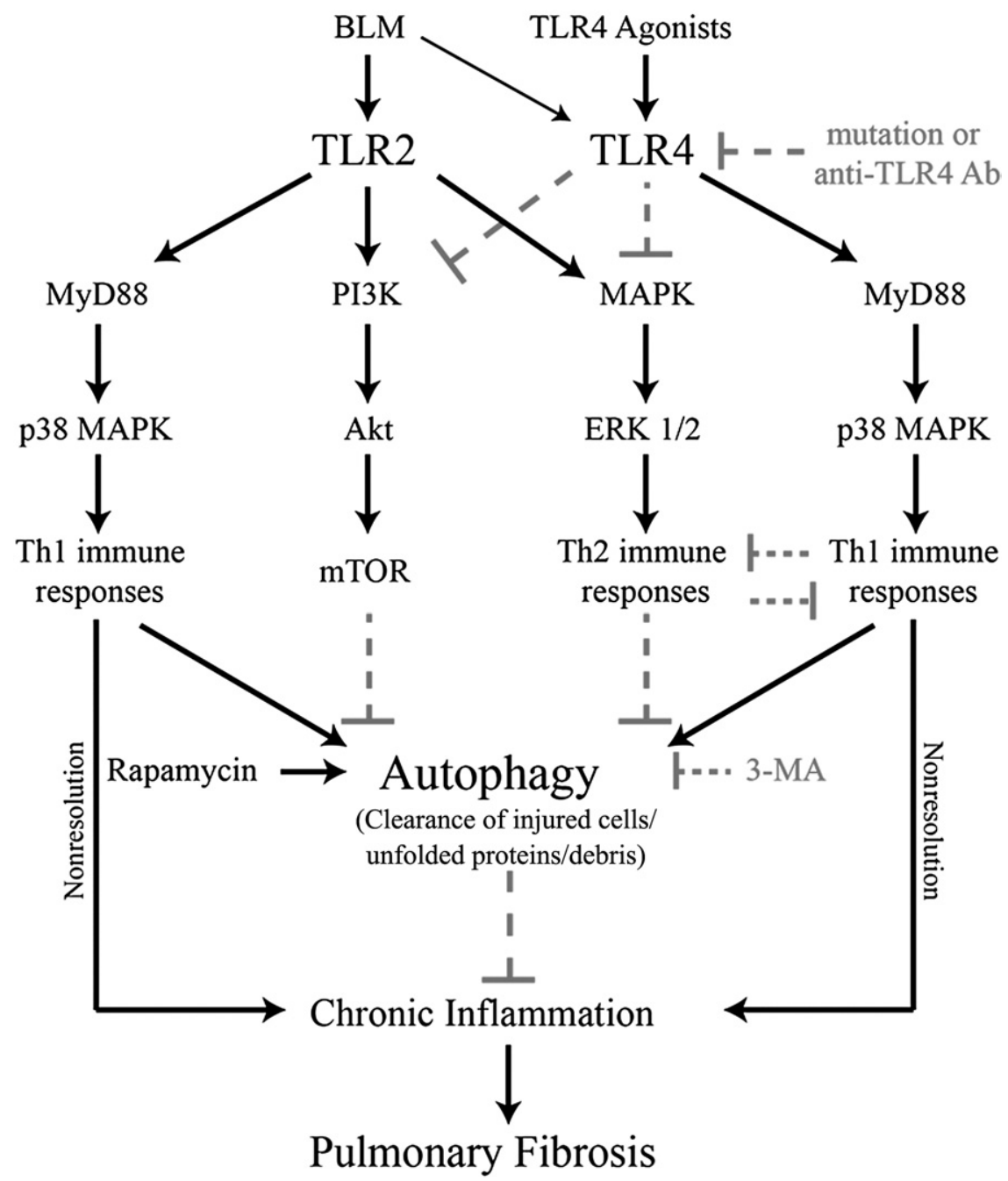

Figure 9. Schematic diagram illustrates the mechanisms by which targeting TLR 4 directs the resolution of pulmonary inflammation and fibrosis via regulation of autophagy. Bleomycin (BLM) is a specific agonist of TLR2 and causes severe lung injury, oxygenic stress, and a potent Th1 inflammatory response through direct activation of TLR2 and, to a certain degree, TLR4. The BLM-induced acute lung injury and inflammation gradually subside and become less severe, and pulmonary fibrosis may not develop if the TLR2-mediated inflammation resolves in time. Otherwise, chronic inflammation develops and is sustained, which drives the progression of pulmonary fibrosis. Genetic or pharmacologic inhibition of TLR2 activity protects against the BLM-induced pulmonary inflammation and fibrosis. ${ }^{11}$ However basal TLR4 activity activates autophagy in the BLM-injured lung tissue through inducing the Th1 immune response to the activation of MyD88-dependent TRIF/p38 pathways and reducing Th2 immune response to the attenuation of the ERK signaling pathway. Moreover, the basal TLR4 activity can also activate autophagy via the inhibition of the PI3kinase-Akt-mammalian target of rapamycin (mTOR) signaling pathway. The activated autophagy is critically required for clearing injured cells, unfolded proteins, and debris from the BLM-injured lung tissue. Activation of autophagy by rapamycin, or inhibition of autophagy by 3-MA, can reverse the pro- or antifibrotic role of TLR4 activation- or antagonism-regulated fibrogenesis, respectively. Ab, antibody; 3-MA, 3-methyadenine.

lungs. ${ }^{32}$ Additionally, the TLR4 agonist LPS suppresses asthma-like pulmonary inflammation and Th2 responses via TLR4-dependent nitric oxide synthase 2 activity, whereas TLR4 deficiency causes pulmonary emphysema resulting from increased oxidant generation and elastoIytic activity. ${ }^{38}$

On the other hand, there are several reports that TLR4 activation is associated with the development of tissue fibrosis. For example, bacterial components such as LPS promote TGF- $\beta 1$-stimulated fibrogenesis in liver tissue. ${ }^{14,39}$ Inhibition of TLR4 signaling prevents LPS-induced pulmonary fibrosis. ${ }^{40}$ TLR4 deficiency reduces $\alpha$-SMA expression, fibroblast accumulation, and renal fibrosis induced by unilateral ureteral obstruction. ${ }^{41}$

The apparently contradictory effects of TLR4 activity on the resolution of inflammation and fibrosis seem more than just a consequence of the TLR4-mediated "doubleedged sword" role in the injury/repair processes. Based on others' observations as well as our own, the different regulatory roles of TLR4 activity in the resolution of inflammation and fibrosis in these studies may largely result from the different experimental designs, particularly the different interventional timing. Indeed, the different timing of TLR4 antagonism may produce different thera- peutic efficacy in the various types of tissue injury, inflammation, and fibrosis.

In BLM-induced lung injury as presented in the current study, inhibition of TLR4, both in a prophylactic and a delayed manner, further deteriorates injured lung, sustains chronic inflammation, and promotes the progression of pulmonary fibrosis. However we recently found that prophylactic (including TLR4 knockout) or therapeutic inhibition of TLR4 activity results in either an anti- or a proresolving role in chemotherapeutic agent doxorubicin-induced myocardial injury, cardiac fibrosis, and dysfunction, respectively (unpublished observation). We found that BLM is a specific agonist of TLR2 and that it causes severe lung injury and oxygenic stress and stimulates inflammation through direct activation of TLR2. ${ }^{11}$ Thus it is not possible for prophylactic antagonism of TLR4 activity to block the TLR2-mediated BLM inflammation, so both prophylactic and therapeutic antagonism of TLR4 activity, which is essentially necessary for the resolution of acute inflammation, exacerbates the BLM-induced lung injury, sustains chronic inflammation, and promotes the progression of pulmonary fibrosis (Figure 9). 
In contrast, in the example of doxorubicin-induced myocardial fibrosis and cardiac dysfunction, doxorubicin acting as an agonist of TLR4 stimulates myocardial inflammation and promotes cardiac injury, fibrosis, and cardiac dysfunction. ${ }^{15}$ Thus prophylactic antagonism of TLR4 blocks doxorubicin-induced TLR4 activation and TLR4-mediated inflammation and therefore protects from doxorubicin-induced cardiac injury, fibrosis, and dysfunction. Therapeutic antagonism of TLR4 activity in this model cannot produce an inflammatory-preventing benefit, but it interferes with the TLR4-mediated proresolution of inflammation and cardiac fibrosis.

Indeed, evaluating the therapeutic effectiveness of antifibrotic agents may critically depend on the administered timing of the studied drug/agent in a preventive or in a delayed manner, because an agent with preventive action does not mean that it can produce therapeutic efficacy against tissue fibrosis. Thus many agents, particularly anti-inflammatory agents, have been observed to have antifibrotic effects in preclinical study but failed to produce an antifibrotic response in clinical trials. ${ }^{42}$ It is prudent to point out that it may not be an appropriate or sufficient way to overextend the therapeutic efficacy of blocking or knocking out TLR4 activity on the TLR4 agonist-induced tissue injury, inflammation, and fibrosis, even though chronic inflammation and fibrosis are consequences of the host's complex responses to TLR4 activation.

Based on our and others' observations, activation of TLR4 can induce autophagy by activating the MyD88dependent p38 MAPK pathway and by inhibiting the PI3-kinase-Akt-mTOR pathway, which is a negative regulator of autophagy (Figure 9). Thus our study supports the notion that basal TLR4 activity, particularly TLR4-induced autophagy, is required for early and effective clearance of the injured or dead cells, unfolded/ misfolded proteins, or debris in the injured lung tissue and for the resolution of chronic inflammation and fibrosis after tissue injury. ${ }^{32}$ Indeed, TLR4 activity participates in cytoplasmic sequestration and subsequent recycling or degradation via connecting autophagy to phagocytosis $^{43}$ so that autophagy acts as an effector of TLR4 signaling to eliminate invasive pathogens, apoptotic/dead cells, and debris. Therefore TLR4 acts as a negative regulator of noninfectious lung inflammation induced by low-molecular-weight hyaluronic acid. $^{32}$ In addition, the observations that autophagy acts as an effector of pattern recognition receptors and proinflammatory factors such as Th1 cytokines, whereas immunosuppressive factors such as Th2 cytokines inhibit autophagic activity, ${ }^{9}$ provide deeper insights into the mechanism of Th1/Th2 immune balance that determines the direction of injury repair processes after acute tissue injury-either promoting resolution or maintaining chronic inflammation and fibrosis progression. ${ }^{10,44}$

Our studies demonstrate that TLR4-mediated autophagy plays a critical protective role in the proresolution of chronic inflammation and fibrosis as the effector of Th1-type cytokines. Inactivation of autophagy by blockade or deficiency of TLR4 impedes the degradation of collagen, whereas activation of autophagy by TLR4 agonists promotes collagen degradation. Indeed, we recently found that IL-17A sustains chronic inflammation and promotes progression of pulmonary fibrosis through inhibiting autophagy and autophagy-associated cell death after acute lung injury, whereas blocking IL-17A promotes the resolution of inflammation and fibrosis through restoring the suppressed autophagic activity to enhance autophagy-associated cell death and the collagen degradation in the fibrotic tissue. ${ }^{45}$ Our findings that the autophagic inducer rapamycin reverses TLR4 deficiency/blockade-aggravated chronic inflammation and tissue fibrosis, whereas the autophagic inhibitor 3-MA counteracted the therapeutic effects of TLR4 agonist on inflammation and fibrosis are consistent with several recent studies in that deficiency of autophagy is responsible for the absence of collagen degradation and subsequently contributes to the development of tissue fibrosis. ${ }^{46,47}$ Thus our results highlight a course of action in which immunostimulants with autophagy-enhancing activity, rather than immunosuppressive agents, should be used for the treatment of fibroproliferative diseases. ${ }^{48,49}$

In summary, our studies demonstrate that the ongoing immunity mediated by TLR4 signaling is critical for the resolution of inflammation and tissue fibrosis after acute and chronic lung injury, and the findings support a novel approach to the treatment of fibroproliferative lung diseases such as IPF. Thus immunostimulants eliciting autophagic activity rather than immunosuppressive agents with suppressed autophagy should be used for the treatment of fibroproliferative diseases. Also, our study provides a rationale for understanding the failure of anti-inflammatory and immunosuppressive agents in the treatment of IPF. Indeed, recent work demonstrating beneficial effects of IFN- $\gamma$ in patients with IPF provides strong evidence to support our proposed mechanism: IFN- $\gamma$ is a Th1 cytokine and a potent activator of autophagy. ${ }^{50,51}$

\section{References}

1. Rosenbloom J, Castro SV, Jimenez SA: Narrative review: fibrotic diseases: cellular and molecular mechanisms and novel therapies. Ann Intern Med 2010, 152:159-166

2. du Bois RM: Strategies for treating idiopathic pulmonary fibrosis. Nat Rev Drug Discov 2010, 9:129-140

3. de Andrade JA, Thannickal VJ: Innovative approaches to the therapy of fibrosis. Curr Opin Rheumatol 2009, 21:649-655

4. Boucher RC: Idiopathic pulmonary fibrosis-a sticky business. N Engl J Med 2011, 364:1560-1561

5. Datta A, Scotton CJ, Chambers RC: Novel therapeutic approaches for pulmonary fibrosis. Br J Pharmacol 2011, 163:141-72

6. Perazella MA, Markowitz GS: Drug-induced acute interstitial nephritis Nat Rev Nephrol 2010, 6:461-470

7. Zisman DA, Schwarz M, Anstrom KJ, Collard HR, Flaherty KR, Hunninghake GW: A controlled trial of sildenafil in advanced idiopathic pulmonary fibrosis. N Engl J Med 2010, 363:620-628

8. Strieter RM, Mehrad B: New mechanisms of pulmonary fibrosis. Chest 2009, 136:1364-1370

9. Delgado M, Singh S, De Haro S, Master S, Ponpuak M, Dinkins C, Ornatowski W, Vergne I, Deretic V: Autophagy and pattern recognition receptors in innate immunity. Immunol Rev 2009, 227:189-202 
10. Wynn TA: Common and unique mechanisms regulate fibrosis in various fibroproliferative diseases. J Clin Invest 2007, 117:524-529

11. Yang HZ, Cui B, Liu HZ, Chen ZR, Yan HM, Hua F, Hu ZW: Targeting TLR2 attenuates pulmonary inflammation and fibrosis by reversion of suppressive immune microenvironment. J Immunol 2009, 182:692702

12. Williams AS, Leung SY, Nath $P$, Khorasani NM, Bhavsar $P$, Issa R, Mitchell JA, Adcock IM, Chung KF: Role of TLR2, TLR4, and MyD88 in murine ozone-induced airway hyperresponsiveness and neutrophilia. J Appl Physiol 2007, 103:1189-1195

13. Imai $Y$, Kuba K, Neely GG, Yaghubian-Malhami R, Perkmann $T$, van Loo G, Ermolaeva M, Veldhuizen R, Leung YH, Wang H, Liu H, Sun Y, Pasparakis M, Kopf M, Mech C, Bavari S, Peiris JS, Slutsky AS, Akira S, Hultqvist M, Holmdahl R, Nicholls J, Jiang C, Binder CJ, Penninger JM: Identification of oxidative stress and Toll-like receptor 4 signaling as a key pathway of acute lung injury. Cell 2008, 133:235-249

14. Seki E, De Minicis S, Osterreicher CH, Kluwe J, Osawa Y, Brenner DA, Schwabe RF: TLR4 enhances TGF- $\beta$ signaling and hepatic fibrosis. Nat Med 2007, 13:1324-1332

15. Timmers L, Sluijter JP, van Keulen JK, Hoefer IE, Nederhoff MG, Goumans MJ, Doevendans PA, van Echteld CJ, Joles JA, Quax PH, Piek JJ, Pasterkamp G, de Kleijn DP: Toll-like receptor 4 mediates maladaptive left ventricular remodeling and impairs cardiac function after myocardial infarction. Circ Res 2008, 102:257-264

16. Liu YY, Cai WF, Yang HZ, Cui B, Chen ZR, Liu HZ, Yan J, Jin W, Yan HM, Xin BM, Yuan B, Hua F, Hu ZW: Bacillus Calmette-Guerin and TLR4 agonist prevent cardiovascular hypertrophy and fibrosis by regulating immune microenvironment. J Immunol 2008, 180:7349_ 7357

17. Yang HZ, Cui B, Liu HZ, Mi S, Yan J, Yan HM, Hua F, Lin H, Cai WF, Xie WJ, Lv XX, Wang XX, Xin BM, Zhan QM, Hu ZW: Blocking TLR2 activity attenuates pulmonary metastases of tumor. PLoS ONE 2009, 4:e6520

18. Moeller A, Ask K, Warburton D, Gauldie J, Kolb M: The bleomycin animal model: a useful tool to investigate treatment options for idiopathic pulmonary fibrosis Int J Biochem Cell Biol 2008, 40:362-382

19. Vanoirbeek JA, Rinaldi M, De Vooght V, Haenen S, Bobic S, GayanRamirez G, Hoet PH, Verbeken E, Decramer M, Nemery B, Janssens $W$ : Noninvasive and invasive pulmonary function in mouse models of obstructive and restrictive respiratory diseases. Am J Respir Cell Mo Biol 2009, 42:96-104

20. Shofer S, Badea C, Qi Y, Potts E, Foster WM, Johnson GA: A micro-CT analysis of murine lung recruitment in bleomycin-induced lung injury. J Appl Physiol 2008, 105:669-677

21. Traidl-Hoffmann C, Mariani V, Hochrein H, Karg K, Wagner H, Ring J, Mueller MJ, Jakob T, Behrendt H: Pollen-associated phytoprostanes inhibit dendritic cell interleukin-12 production and augment $\mathrm{T}$ helper type 2 cell polarization. J Exp Med 2005, 201:627-636

22. Hamacher-Brady A, Brady NR, Logue SE, Sayen MR, Jinno M, Kirshenbaum LA, Gottlieb RA, Gustafsson AB: Response to myocardial ischemia/reperfusion injury involves Bnip3 and autophagy. Cell Death Differ 2007, 14:146-157

23. Atabai K, Jame S, Azhar N, Kuo A, Lam M, McKleroy W, Dehart G, Rahman S, Xia DD, Melton AC, Wolters P, Emson CL, Turner SM, Werb Z, Sheppard D: Mfge8 diminishes the severity of tissue fibrosis in mice by binding and targeting collagen for uptake by macrophages. J Clin Invest 2009, 119:3713-3722

24. Chen JX, Stinnett A: Critical role of the NADPH oxidase subunit p47phox on vascular TLR expression and neointimal lesion formation in high-fat diet-induced obesity. Lab Invest 2008, 88:1316-1328

25. Xu Y, Jagannath C, Liu XD, Sharafkhaneh A, Kolodziejska KE, Eissa NT: Toll-like receptor 4 is a sensor for autophagy associated with innate immunity. Immunity 2007, 27:135-144

26. Korolchuk VI, Saiki S, Lichtenberg M, Siddiqi FH, Roberts EA, Imarisio S, Jahreiss L, Sarkar S, Futter M, Menzies FM, O'Kane CJ, Deretic V, Rubinsztein DC: Lysosomal positioning coordinates cellular nutrient responses. Nat Cell Biol 2011, 13:453-460

27. Salazar M, Carracedo A, Salanueva IJ, Hernandez-Tiedra S, Lorente M, Egia A, Vazquez P, Blazquez C, Torres S, Garcia S, Nowak J, Fimia GM, Piacentini M, Cecconi F, Pandolfi PP, Gonzalez-Feria L, Iovanna JL, Guzman M, Boya P, Velasco G: Cannabinoid action induces autophagy-mediated cell death through stimulation of ER stress in human glioma cells. J Clin Invest 2009, 119:1359-1372
28. Chhikara M, Wang S, Kern SJ, Ferreyra GA, Barb JJ, Munson PJ, Danner RL: Carbon monoxide blocks lipopolysaccharide-induced gene expression by interfering with proximal TLR4 to NF-kappaB signal transduction in human monocytes. PLoS ONE 2009 4:e8139

29. Mungunsukh O, Griffin AJ, Lee YH, Day RM: Bleomycin induces the extrinsic apoptotic pathway in pulmonary endothelial cells. Am J Physiol Lung Cell Mol Physiol 2010, 298:L696-L703

30. Kim KW, Hwang M, Moretti L, Jaboin JJ, Cha YI, Lu B: Autophagy upregulation by inhibitors of caspase- 3 and mTOR enhances radiotherapy in a mouse model of lung cancer. Autophagy 2008, 4:659668

31. Serhan CN, Brain SD, Buckley CD, Gilroy DW, Haslett C, O'Neill LA, Perretti M, Rossi AG, Wallace JL: Resolution of inflammation: state of the art, definitions and terms. FASEB J 2007, 21:325-332

32. Zhao H, Leu SW, Shi L, Dedaj R, Zhao G, Garg HG, Shen L, Lien E, Fitzgerald KA, Shiedlin A, Shen H, Quinn DA, Hales CA: TLR4 is a negative regulator in noninfectious lung inflammation. J Immunol 2010, 184:5308-5314

33. Canale-Zambrano JC, Auger ML, Haston CK: Toll-like receptor-4 genotype influences the survival of cystic fibrosis mice. Am J Physiol Gastrointest Liver Physiol 2010, 299:G381-G390

34. John G, Yildirim AO, Rubin BK, Gruenert DC, Henke MO: TLR-4mediated innate immunity is reduced in cystic fibrosis airway cells. Am J Respir Cell Mol Biol 2010, 42:424-431

35. Lembo A, Pelletier M, Iyer R, Timko M, Dudda JC, West TE, Wilson CB, Hajjar AM, Skerrett SJ: Administration of a synthetic TLR4 agonist protects mice from pneumonic tularemia. J Immunol 2008, 180:75747581

36. Gariboldi S, Palazzo M, Zanobbio L, Selleri S, Sommariva M, Sfondrini L, Cavicchini S, Balsari A, Rumio C: Low molecular weight hyaluronic acid increases the self-defense of skin epithelium by induction of beta-defensin 2 via TLR2 and TLR4. J Immunol 2008, 181:2103-2110

37. Jiang D, Liang J, Noble PW: Hyaluronan in tissue injury and repair Annu Rev Cell Dev Biol 2007, 23:435-461

38. Zhang X, Shan P, Jiang G, Cohn L, Lee PJ: Toll-like receptor 4 deficiency causes pulmonary emphysema. J Clin Invest 2006, 116: 3050-3059

39. Luedde $T$, Trautwein C: A molecular link between inflammation and fibrogenesis: the bacterial microflora influences hepatic fibrosis via toll-like receptor 4-dependent modification of transforming growth factor-beta signaling in hepatic stellate cells. Hepatology 2008, 47: 1089-1091

40. He Z, Zhu $\mathrm{Y}$, Jiang $\mathrm{H}$ : Inhibiting toll-like receptor 4 signaling ameliorates pulmonary fibrosis during acute lung injury induced by lipopolysaccharide: an experimental study. Respir Res 2009, 10: 126

41. Campbell MT, Hile KL, Zhang $H$, Asanuma $H$, Vanderbrink BA, Rink RR, Meldrum KK: Toll-Like receptor 4: a novel signaling pathway during renal fibrogenesis. J Surg Res 2009, 156:1-9

42. Thannickal VJ, Roman J: Challenges in translating preclinical studies to effective drug therapies in idiopathic pulmonary fibrosis. Am J Respir Crit Care Med 2010, 181:532-533

43. Sanjuan MA, Dillon CP, Tait SW, Moshiach S, Dorsey F, Connell S, Komatsu M, Tanaka K, Cleveland JL, Withoff S, Green DR: Toll-like receptor signalling in macrophages links the autophagy pathway to phagocytosis. Nature 2007, 450:1253-1257

44. Wynn TA: Fibrotic disease and the $T(H) 1 / T(H) 2$ paradigm. Nat Rev Immunol 2004, 4:583-594

45. Mi S, Li Z, Yang HZ, Liu H, Wang JP, Ma YG, Wang XX, Liu HZ, Sun W, Hu ZW: Blocking IL-17A promotes the resolution of pulmonary inflammation and fibrosis via TGF-beta1-dependent and -independent mechanisms. J Immunol 2011, 187:3003-3014

46. Luciani A, Villella VR, Esposito S, Brunetti-Pierri N, Medina DL, Settembre C, Gavina M, Raia V, Ballabio A, Maiuri L: Cystic fibrosis: a disorder with defective autophagy. Autophagy 2010, 7:104-106

47. Luciani A, Villella VR, Esposito S, Brunetti-Pierri N, Medina D, Settembre C, Gavina M, Pulze L, Giardino I, Pettoello-Mantovani M, D'Apolito M, Guido S, Masliah E, Spencer B, Quaratino S, Raia V, Ballabio A, Maiuri L: Defective CFTR induces aggresome formation and lung inflammation in cystic fibrosis through ROS-mediated autophagy inhibition. Nat Cell Biol 2010, 12:863-875 
48. Hidvegi T, Ewing M, Hale P, Dippold C, Beckett C, Kemp C, Maurice N, Mukherjee A, Goldbach C, Watkins S, Michalopoulos G, Perlmutter $\mathrm{DH}$ : An autophagy-enhancing drug promotes degradation of mutant alpha1-antitrypsin Z and reduces hepatic fibrosis. Science 2010, 329:229-232

49. Sifers RN: Medicine. Clearing conformational disease. Science. 2010, 329:154-155
50. Bouros D: Interferon gamma for idiopathic pulmonary fibrosis. Lancet 2009, 374:180-182

51. King TE Jr, Albera C, Bradford WZ, Costabel U, Hormel P, Lancaster L, Noble PW, Sahn SA, Szwarcberg J, Thomeer M, Valeyre D, du Bois $\mathrm{RM}$ : Effect of interferon gamma-1b on survival in patients with idiopathic pulmonary fibrosis (INSPIRE): a multicentre, randomised, placebo-controlled trial. Lancet 2009, 374:222-228 